\title{
Mouse $\gamma$-Synuclein Promoter-Mediated Gene Expression and Editing in Mammalian Retinal Ganglion Cells
}

\author{
Qizhao Wang, ${ }^{1 *}$ Pei Zhuang, ${ }^{1 *}$ Haoliang Huang, ${ }^{1}$ Liang Li, ${ }^{1}$ Liang Liu, ${ }^{1}$ Hannah C. Webber, ${ }^{1}$ Roopa Dalal, ${ }^{1}$ \\ Leonard Siew, ${ }^{1}$ Clarisse M. Fligor, ${ }^{2}{ }^{\circledR}$ Kun-Che Chang, ${ }^{1}$ Michael Nahmou, ${ }^{1}$ Alexander Kreymerman, ${ }^{1}$ Yang Sun, ${ }^{1}$ \\ Jason S. Meyer, ${ }^{2}{ }^{\circledR}$ Jeffrey Louis Goldberg, ${ }^{1}$ and ${ }^{\circledR}$ Yang $\mathrm{Hu}^{1}$ \\ ${ }^{1}$ Department of Ophthalmology, Stanford University School of Medicine, Palo Alto, California 94304, and ${ }^{2}$ Department of Biology, Indiana \\ University Purdue University Indianapolis, Indianapolis, Indiana 46202
}

Optic neuropathies are a group of optic nerve $(\mathrm{ON})$ diseases caused by various insults including glaucoma, inflammation, ischemia, trauma, and genetic deficits, which are characterized by retinal ganglion cell (RGC) death and ON degeneration. An increasing number of genes involved in RGC intrinsic signaling have been found to be promising neural repair targets that can potentially be modulated directly by gene therapy, if we can achieve RGC specific gene targeting. To address this challenge, we first used adeno-associated virus (AAV)-mediated gene transfer to perform a low-throughput in vivo screening in both male and female mouse eyes and identified the mouse $\gamma$-synuclein $(\mathrm{mSncg})$ promoter, which specifically and potently sustained transgene expression in mouse RGCs and also works in human RGCs. We further demonstrated that gene therapy that combines AAV-mSncg promoter with clustered regularly interspaced short palindromic repeats (CRISPR)/Cas9 gene editing can knock down pro-degenerative genes in RGCs and provide effective neuroprotection in optic neuropathies.

Key words: AAV; CRSPR; neuroprotection; optic nerve; RGC; Sncg

Significance Statement

Here, we present an RGC-specific promoter, mouse $\gamma$-synuclein (mSncg) promoter, and perform extensive characterization and proof-of-concept studies of mSncg promoter-mediated gene expression and clustered regularly interspaced short palindromic repeats (CRISPR)/Cas9 gene editing in RGCs in vivo. To our knowledge, this is the first report demonstrating in vivo neuroprotection of injured RGCs and optic nerve (ON) by AAV-mediated CRISPR/Cas9 inhibition of genes that are critical for neurodegeneration. It represents a powerful tool to achieve RGC-specific gene modulation, and also opens up a promising gene therapy strategy for optic neuropathies, the most common form of eye diseases that cause irreversible blindness.

\section{Introduction}

Optic neuropathies are a group of optic nerve $(\mathrm{ON})$ diseases characterized by the progressive death of retinal ganglion cells

\footnotetext{
Received Jan. 14, 2020; revised Mar. 28, 2020; accepted Apr. 2, 2020.

Author contributions: Q.W., P.Z., H.H., L.Li, and Y.H. designed research; Q.W., P.Z., H.H., L.Li, L.Liu, H.C.W., R.D., L.S., C.M.F., K.-C.C., M.N., A.K., J.S.M., J.L.G., and Y.H. performed research; Y.S., J.L.G., and Y.H. contributed unpublished reagents/analytic tools; Q.W., P.Z., H.H., L.Li, L.Liu, C.M.F., J.S.M., and Y.H. analyzed data; Q.W., P.Z., H.H., L.Li, and Y.H. wrote the paper.

${ }^{*} Q$.W. and P.Z. are co-first authors.

Y.H. is supported by National Institutes of Health (NIH) Grants EY024932, EY023295, and EY028106; grants from the BrightFocus Foundation, the Glaucoma Research Foundation, and the National Multiple Sclerosis Society; and by an RPB William \& Mary Greve Special Scholar Award. Portions of this work were supported by NIH Grants U24-EY029903, EY026766 and EY027261 (to J.L.G.), NIH Grant EY024984 (to J.S.M.), and NIH Grants EY-25295 and K08-EY022058 and Veterans Affairs Grant CX001298 and the Ziegler Foundation for the Blind (to Y.S.), who is a Stanford Child Health Research Institute Laurie Kraus Lacob Faculty Scholar. An unrestricted grant from Research to Prevent Blindness and NEI P30-026877 supported the Department of Ophthalmology.

The authors declare no competing financial interests.

Acknowledgements: We thank Dr. Alan Tessler, Dr. Zhigang He, and Dr. Jie Zhang for critically reading this manuscript. We also thank Dr. Stanley Qi's and Dr. Xueqiu Lin's help on off-target analysis.

Correspondence should be addressed to Yang Hu at huyang@stanford.edu.

https://doi.org/10.1523/JNEUROSCI.0102-20.2020

Copyright $\odot 2020$ the authors
}

(RGCs) and ON degeneration, which are the leading causes of irreversible blindness (Carelli et al., 2017; DeBusk and Moster, 2018). RGCs relay visual information from retina to brain through the ON, which is formed by RGCs' projection axons. The ON is highly vulnerable to injury by inflammation, ischemia, toxicity, hereditary deficits and high intraocular pressure, any of which can cause retrograde RGC death. Optic neuropathy can also be associated with other CNS neurodegenerative diseases (Carelli et al., 2017), including multiple sclerosis (Talman, 2010; Toosy et al., 2014; Balcer et al., 2015), Alzheimer's disease (McKinnon, 2003; Chiasseu et al., 2016), and amyotrophic lateral sclerosis (Minegishi et al., 2016; Wiggs and Pasquale, 2017). Lack of effective neuroprotective or regenerative therapy for RGCs and $\mathrm{ON}$ significantly impedes preservation of vision in patients with optic neuropathies, and novel treatments are desperately needed.

Gene therapy using a viral vehicle to deliver genetic material into cells is a promising way to directly target pathogenetic molecules (Keeler et al., 2017). The retina is an advantageous target for gene therapy due to its easy access, confined non-systemic 
localization, partial immune privilege, and well-established definitive functional readouts (Ratican et al., 2018). The success of adeno-associated virus (AAV)-mediated gene replacement in treating inherited retinal disease (Bainbridge et al., 2008; Hauswirth et al., 2008; Maguire et al., 2008, 2009; Busskamp et al., 2010; Gorbatyuk et al., 2010; Mingozzi and High, 2011; Boye et al., 2013; Smalley, 2017) makes RGC-specific gene expression and editing by AAV a promising gene therapy strategy for optic neuropathies. We and others have found that AAV2, the bestcharacterized AAV serotype, efficiently infects RGCs in retina after intravitreal injection; RGCs are located in the innermost layer of the retina, which is directly opposed to the vitreous (Pang et al., 2008; Park et al., 2008; Hu et al., 2012; Boye et al., 2013; Yang et al., 2014, 2016a; Miao et al., 2016). However, other cell types, including amacrine cells, Müller glia, and bipolar cells, can also be infected, although to a lesser degree (Pang et al., 2008; Nickells et al., 2017). Therefore, one critical requirement for safe clinical treatment of RGCs by AAV-mediated gene therapy is to achieve precise targeting and sustained gene expression in RGCs without unwanted gene expression in other retinal cells.

The clustered regularly interspaced short palindromic repeats (CRISPR) and CRISPR-associated protein (Cas) system, which bacteria use to edit foreign viral gene intrusion, has been adapted for efficient gene editing of the mammalian genome (Cong et al., 2013; Jinek et al., 2013; Mali et al., 2013). Mature retinal neurons are post-mitotic cells, in which specific gene deletion can be achieved by CRISPR/Cas9-mediated double-stranded DNA breaks and nonhomologous end joining (Wang et al., 2014b; Bakondi et al., 2016). The simplicity and specificity of the RNAguided CRISPR/Cas9 endonuclease system has revolutionized gene therapy by enabling precise, efficient and even multiplex gene editing in mammalian cells. Taking advantage of these powerful genetic tools to develop neuroprotective treatments for optic neuropathy is a scientifically important and clinically urgent undertaking.

We reasoned that an RGC-specific promoter would allow us to precisely manipulate RGC gene expression without affecting other retinal cell types. Here, we report that mouse $\gamma$-synuclein (mSncg) promoter drives specific, potent, and sustained transgene expression in rodent RGCs. We also demonstrate, for the first time in vivo in mouse RGCs, that AAV2-mSncg promoterdriven CRISPR/Cas9 can significantly knock-down endogenous DNA-damage inducible transcript 3 (Ddit3; gene name for the transcription factor CHOP) and Sarm1 and preserve the acutely injured RGC somata and axons. This proof-of-concept study demonstrates that AAV-mediated CRISPR gene therapy using an RGC-specific promoter to directly modulate endogenous degenerative genes holds great potential in treating devastating optic neuropathies.

\section{Materials and Methods}

Mice

C57BL/6 WT (\#000664) mice and H11 ${ }^{\text {LSL-3xFlag-Cas9 }}$ with C57BL/6 background (\#027632; Chiou et al., 2015) were purchased from The Jackson Laboratory. Either sex was randomly used in the experiments. All experimental procedures were performed in compliance with animal protocols approved by the IACUC at Stanford University School of Medicine.

\section{Constructs}

All the promoter constructs were based on the pAM-AAV-CAG-EGFPWPRE plasmid. Genomic DNA (gDNA) from C57BL/6J mouse tails and human HEK 293 cells were used to PCR the nine mouse promoters [mSncg; a-calcium/calmodulin-dependent protein kinase II (mCaMKIIa); ISL LIM homeobox 2 (mIsl2); thy-1 cell surface antigen (mThy1); Class
III $\beta$-tubulin (mTuBB3); Synapsin I (mSynI); phosphoglycerate kinase 1 (mPGK); growth associated protein 43 (mGAP43); and RNA-binding protein with multiple splicing (mRBPMS)] and the four human promoters (hSncg, hIsl2, hThyl, and hSynI), respectively. All the promoters' sequences are included in Extended Data Fig. 1-1. The primers used for PCR with the promoters are shown in Extended Data Fig. 1-2. The promoters were inserted into NdeI and EcoRI sites of pAM-AAV-CAG-EGFPWPRE plasmid to replace the original CAG promoter but partially keep $\mathrm{CMV}$ enhancer. The truncation of mSncg promoter was also done by PCR using the primers listed in Extended Data Fig. 1-2. As we failed to amplify the mRBPMS promoter by PCR, a 2475-bp fragment was synthesized by Integrated DNA Technologies, Inc (IDT).

\section{AAV production}

The detailed procedure has been described previously (Hu et al., 2012; Yang et al., 2014). Briefly, AAV plasmids containing the transgenes were co-transfected with pAAV2 (pACG2)-RC triple mutant (Y444, 500, 730F; Petrs-Silva et al., 2011; Wang et al., 2014a; Zhang et al., 2014) and the pHelper plasmid (Stratagene) into HEK293T cells. All the AAV used in this manuscript were generated the same way; $72 \mathrm{~h}$ after transfection, the cells were lysed to release the viral particles, which were precipitated by $40 \%$ polyethylene glycol and purified by two rounds of cesium chloride density gradient centrifugation. The virus bands were taken out for dialysis in a MWCO 7000 Slide-A -LYZER cassette (Pierce) overnight at $4^{\circ} \mathrm{C}$. The AAV titers were determined by real-time PCR (Extended Data Fig. $1-2)$ and diluted to $1.5 \times 1012$ vector genome $(\mathrm{vg}) / \mathrm{ml}$. Thus, we used $2 \mu \mathrm{l}$ for intravitreal injection of each eye to achieve $3 \times 109 \mathrm{vg} / \mathrm{ret}-$ ina. All the AAVs titers are summarized in Extended Data Fig. 1-2.

\section{Intravitreal injection}

Mice were anesthetized by xylazine and ketamine based on their body weight ( $0.01 \mathrm{mg}$ xylazine/g $+0.08 \mathrm{mg}$ ketamine/g). For each AAV intravitreal injection, a micropipette was inserted into the peripheral retina of three- to eight-week-old mice just behind the ora serrata, and advanced into the vitreous chamber so as to avoid damage to the lens. Approximately $2 \mu \mathrm{l}$ of the vitreous was removed before injection of $2 \mu \mathrm{l}$ AAV into the vitreous chamber.

Immunohistochemistry of wholemount and cross sections of retina After transcardiac perfusion with $4 \%$ PFA in PBS, the eyes were dissected out, postfixed with $4 \%$ PFA for $2 \mathrm{~h}$, at room temperature, and cryoprotected in 30\% sucrose overnight. For retina wholemount, retinas were dissected out and washed extensively in PBS before blocking in staining buffer (10\% normal goat serum and $2 \%$ Triton X-100 in PBS) for $1 \mathrm{~h}$. RBPMS guinea pig antibody was made at ProSci according to publications (Kwong et al., 2010; Rodriguez et al., 2014) and used at 1:4000, mouse CHOP (1:50, Cell Signaling Technology), rat HA (clone 3F10, 1:200, Roche), and M2 antibodies for Flag tag (1:200) were diluted in the same staining buffer. Floating retinas were incubated with primary antibodies overnight at $4^{\circ} \mathrm{C}$ and washed three times for $30 \mathrm{~min}$ each with PBS. Secondary antibodies (Cy2, Cy3, or Cy5 conjugated) were then applied (1:200; Jackson ImmunoResearch) and incubated for $1 \mathrm{~h}$ at room temperature. Retinas were again washed three times for $30 \mathrm{~min}$ each with PBS before a cover slip was attached with Fluoromount-G (SouthernBiotech). For cross sections of retina, the eyes were dehydrated in $30 \%$ sucrose solution overnight before embedding in OCT on dry ice. Serial cross sections $(14 \mu \mathrm{m})$ were cut with a Leica cryostat and collected on Superfrost Plus Slides and stored at $-80^{\circ} \mathrm{C}$ until processed.

Counting surviving RGCs in peripheral retina and axons in $O N$

The detailed procedure has been described previously (Hu et al., 2012; Yang et al., 2014; Huang et al., 2017). Briefly, for RGC counting, wholemount retinas were immunostained with the RBPMS antibody, six to nine fields sampled from peripheral regions of each retina using $40 \times$ lens with a Zeiss M2 epifluorescence microscope, and RBPMS ${ }^{+}$RGCs counted by Volocity software (Quorum Technologies). The percentage of RGC survival was calculated as the ratio of surviving RGC numbers in injured eyes compared with contralateral uninjured eyes. To count surviving axon in $\mathrm{ON}$, transverse semi-thin $(1 \mu \mathrm{m})$ sections of ON were cut 


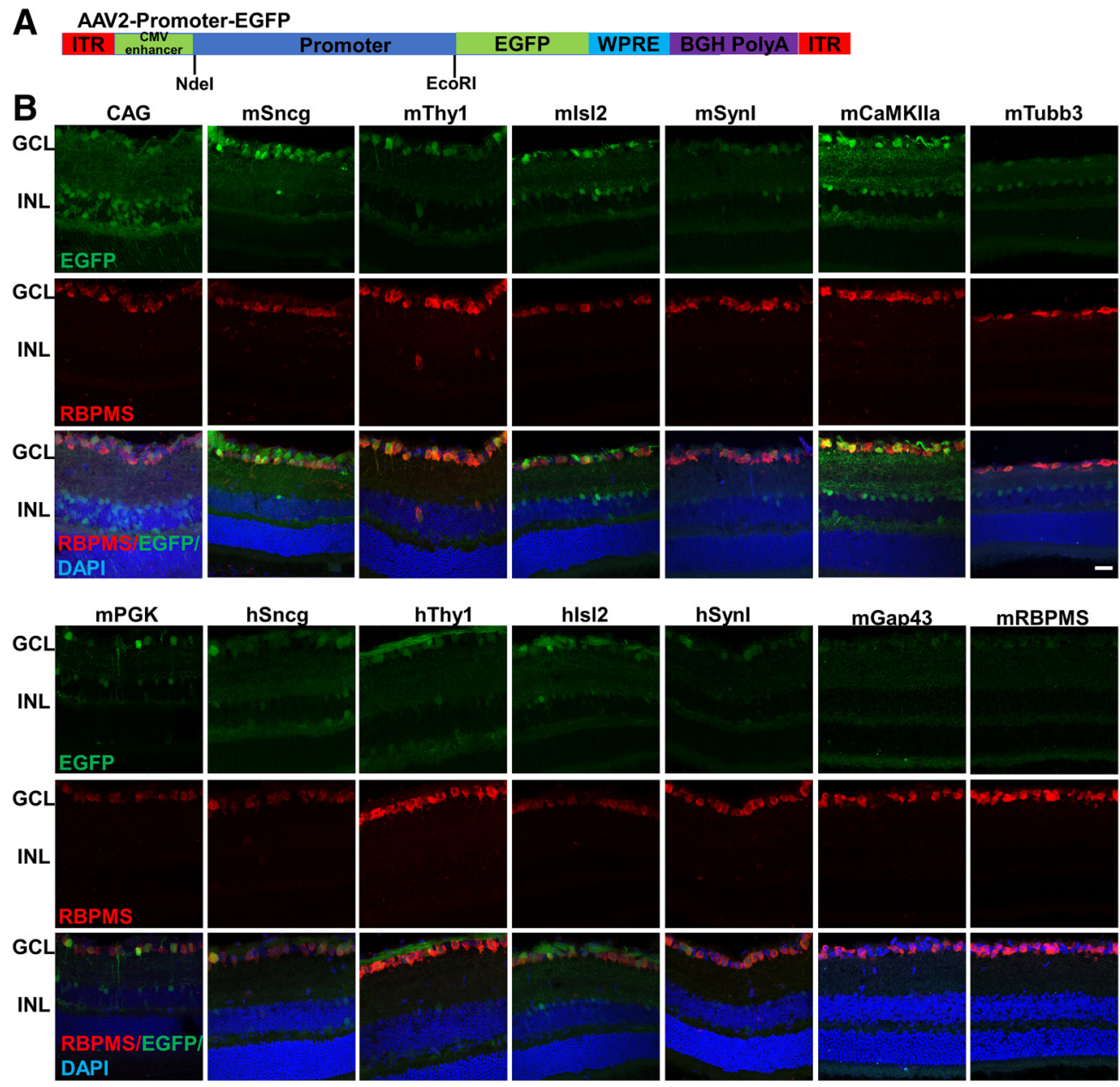

C

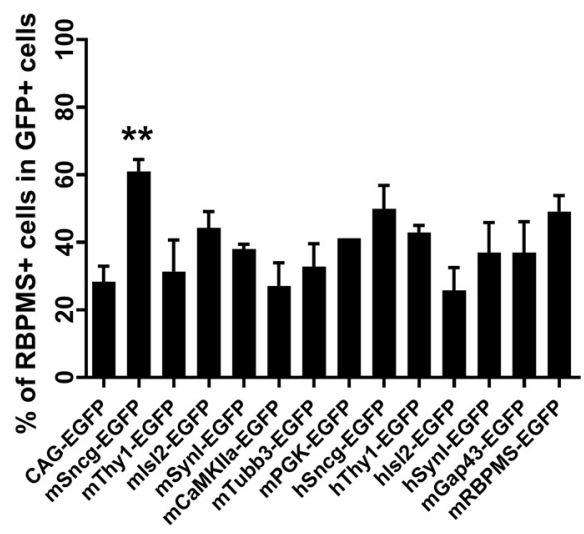

Figure 1. Retinal cross sections showing EGFP expression mediated by AAV2 with diverse promoters. $A$, Diagram of AAV vectors that contain diverse promoters to drive EGFP expression. The promoters' sequences are in Extended Data Figure 1-1 and the primers used to generate these promoters are in Extended Data Figure 1-2. B, Confocal images of retina cross sections showing EGFP expression driven by different promoters. Scale bar, $20 \mu \mathrm{m}$. C, The percentage of RBPMS-positive cells (RGCs) in GFP-positive cells in retinal cryostat sections. Data are presented as mean \pm SEM, $n=3 ;{ }^{* *} p<0.01$; one-way ANOVA with Tukey's post hoc test.

on an ultramicrotome (EM UC7, Leica) and collected $2 \mathrm{~mm}$ distal to the eye ( $\sim 1.5 \mathrm{~mm}$ distal to the crush site). The semi-thin sections were stained with $1 \%$ para-phenylenediamine (PPD) in methanol: isopropanol (1:1; Smith, 2002), and imaged through a $100 \times$ lens of a Zeiss M2 epifluorescence microscope to cover the entire area of the ON without overlap. Two areas of $21.4 \times 29.1 \mu \mathrm{m}$ were cropped from the center of each image, and the surviving axons within the designated areas, roughly $10 \%$ of entire cross-area of one ON, were counted manually. After counting all the images taken from a single nerve, the mean of the surviving axon number was calculated for each $\mathrm{ON}$. The mean of the surviving axon number in the injured $\mathrm{ON}$ was compared with that in the contralateral control $\mathrm{ON}$ to yield a percentage of axon survival value. The investigators who counted the cells or axons were blinded to the treatment of the samples.

\section{Retrograde labeling of RGCs by injection of DiI into superior colliculus} $(\mathrm{SC})$

The adult wild-type (WT) mice were anesthetized by xylazine and ketamine based on their body weight $(0.01 \mathrm{mg}$ xylazine $/ \mathrm{g}+0.08 \mathrm{mg}$ ketamine/g) and placed on a mouse adaptor (502600, World Precision Instruments, LLC) attached to a digital stereotaxic instrument (68025, 

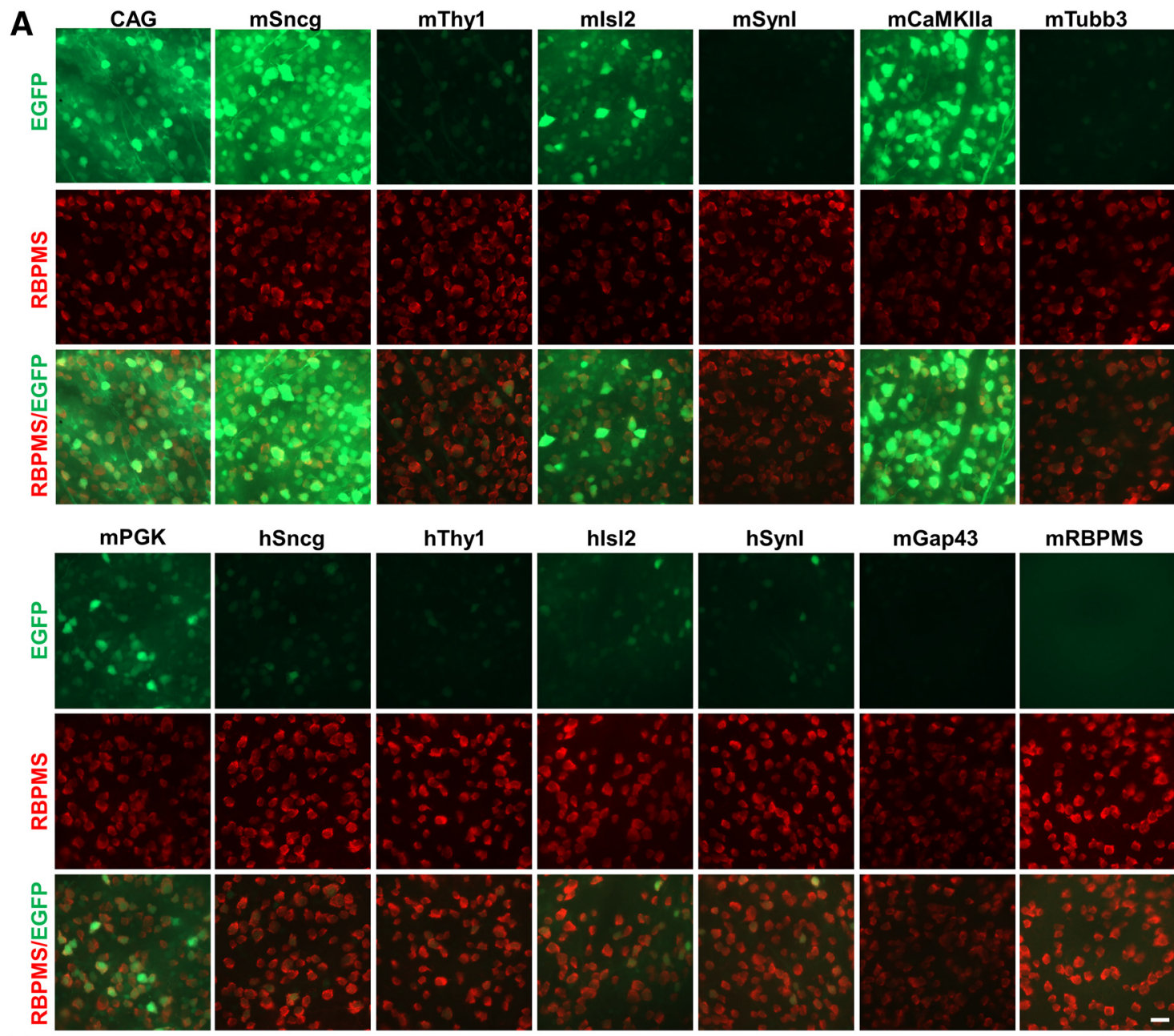

hThy1

hls|2
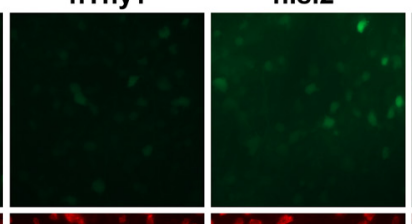

hSynl

mGap43

mRBPMS

B

mSncg-EGFP labeled ON
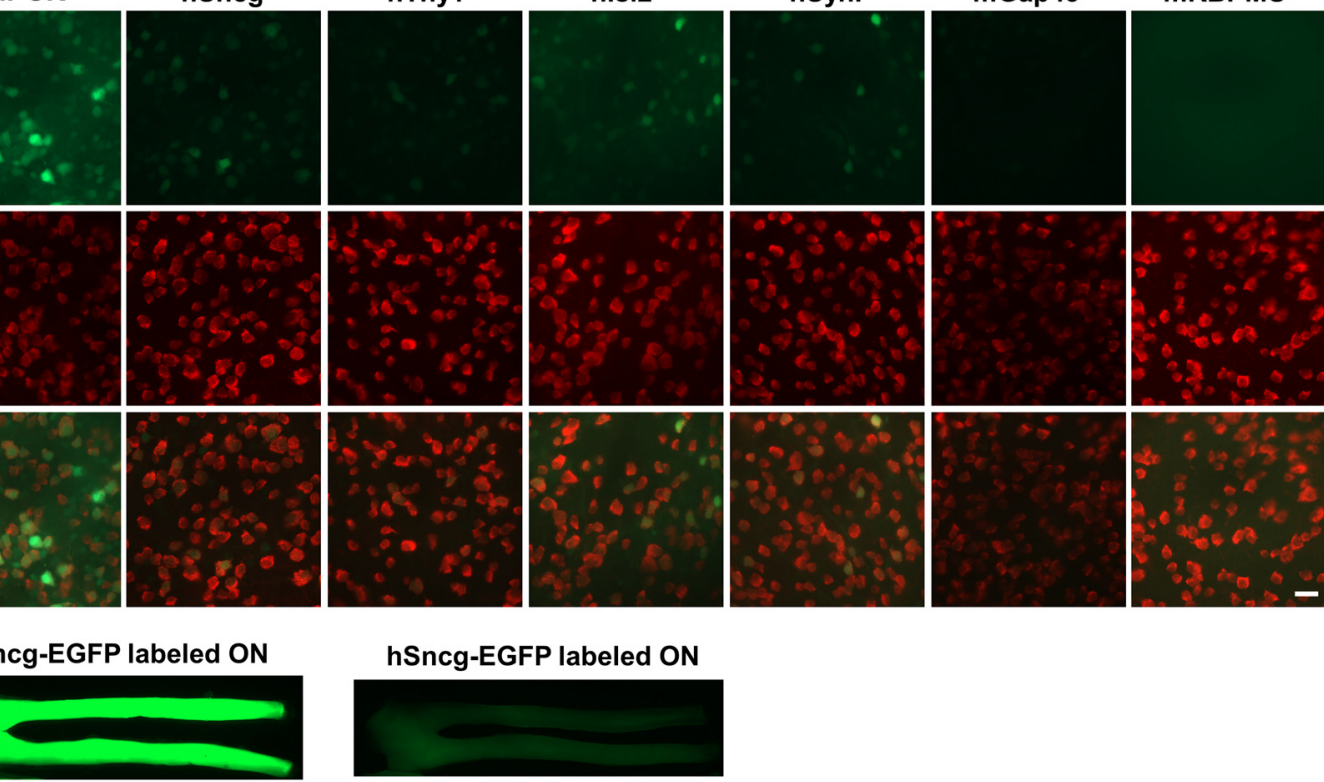

C

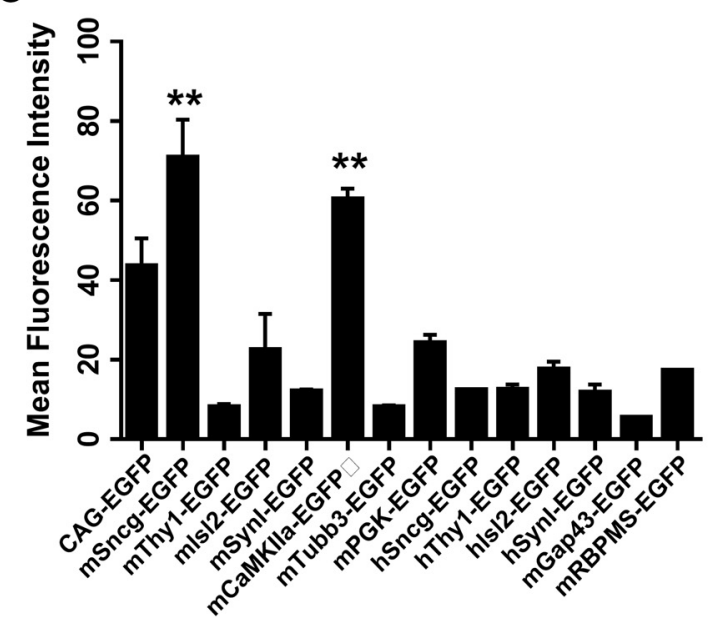

Figure 2. Retinal and ON wholemounts showing EGFP intensities mediated by AAV2 with diverse promoters. $A$, Confocal images of retinal wholemounts showing EGFP expression at varying intensity levels driven by diverse promoters in RGCs. Scale bar, $20 \mu \mathrm{m}$. B, Low-magnification epi-fluorescence images of wholemount ONs containing optic chiasm showing EGFP expression in RGC axons. C, Mean EGFP fluorescence intensity in wholemount retinas. Data are presented as mean \pm SEM, $n=3 ;{ }^{* *} p<0.01$; one-way ANOVA with Tukey's post hoc test. 
RWD Life Science). The bregma was set as the origin of anterior to posterior (AP), medial to lateral (ML), and dorsal to ventral (DV), and the $\lambda$ was at the same ML and DV as bregma. The horizontal plane of the mouse skull was calibrated before drilling by adjusting the left hemisphere point (AP: -2.00 , ML: 2.50) at the same DV with the contralateral point (AP: -2.00 , ML: -2.50 ). The SC coordinates for four sites and three depths are: AP: -3.55 , ML: 0.6, DV: $-1.25 /$ $-1.60 /-2.00$, AP: -3.55 , ML: -0.6 , DV: $-1.25 /-1.60 /-2.00$, AP: -3.92 , ML: 0.8, DV: $-1.25 /-1.60 /-2.00$, and AP: -3.92 , ML: $-0.8, \quad$ DV: $-1.25 /-1.60 /-2.00$. A pulled-glass micropipette fused to a $10-\mu l$ syringe (80314, Hamilton) with hot glue and filled with mineral oil was controlled by micro syringe pump (Micro4, World Precision Instruments, LLC) at the speed of $250 \mathrm{nl} / \mathrm{min}$ for $1 \mathrm{~min}$ per site. Approximately 3- $\mu$ l DiI (V22885, Invitrogen) was injected into both SC. $2 \mathrm{~d}$ after SC injection, the mice were sacrificed, and retinas prepared for wholemount staining.

Fluorescent in situ hybridization (FISH) with retina cross sections

FISH was performed by using the RNAscope Multiplex Fluorescent Detection Reagents V2 (Advanced Cell Diagnostics, ACD) according to the manufacturer's instructions. RNAscope probes $\mathrm{Mm}-\mathrm{Ddit} 3$ and $\mathrm{Mm}$ Sarm1 were purchased from ACD and targeted bases 11-807 and 1011-1966 of mouse Ddit3 and Sarm1 (NCBI reference sequence: NM_007837.3 and NM_001168521.1), respectively. Adult mice were perfused with icecold $4 \% \mathrm{PFA} / \mathrm{PBS}$, eyes were dissected out and fixed in $4 \%$ PFA/PBS at $4^{\circ} \mathrm{C}$ overnight. The eyes were dehydrated with increasing concentrations of sucrose solution (15 $30 \%$ ) overnight before embedding in OCT on dry ice. Serial cross sections $(12 \mu \mathrm{m})$ were cut with a Leica cryostat and collected on Superfrost Plus Slides. The sections were pretreated with protease and then subjected to in situ hybridization with RNAscope Multiplex Fluorescent Detection Reagents V2 according to the manufacturer's instruction (ACD). Briefly, sections were hybridized with the probe solution, followed by amplification and probe detection using TSA plus fluorescein/ cyanine 5 (PerkinElmer). The sections were mounted with Fluoromount-G (SouthernBiotech). Images were captured by a Zeiss LSM 880 confocal laser scanning microscope with $63 \times / 1.40$ Oil DIC (Carl Zeiss Microscopy).

Maintenance of human pluripotent stem cells (hPSCs)

hPSCs were initially maintained in an undifferentiated state as previously described (Ohlemacher et al., 2015, 2016). Briefly, cells were maintained in the undifferentiated state in mTeSR 1 medium on a Matrigel substrate. Upon reaching $\sim 70 \%$ confluency, cells were mechanically passaged with dispase $(2 \mathrm{mg} / \mathrm{ml})$ and split at a ratio of 1:6.

\section{Differentiation of RGCs from $h P S C s$}

hPSCs were differentiated to a retinal lineage following established protocols (Ohlemacher et al., 2015, 2016) with presumptive RGCs identified by a BRN3B:tdTomato reporter (Sluch et al., 2017). After $45 \mathrm{~d}$ of dif-

A

B
hPSC-derived human RGCs

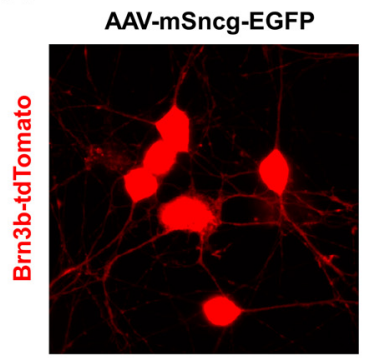
AAV-hSncg-EGFP
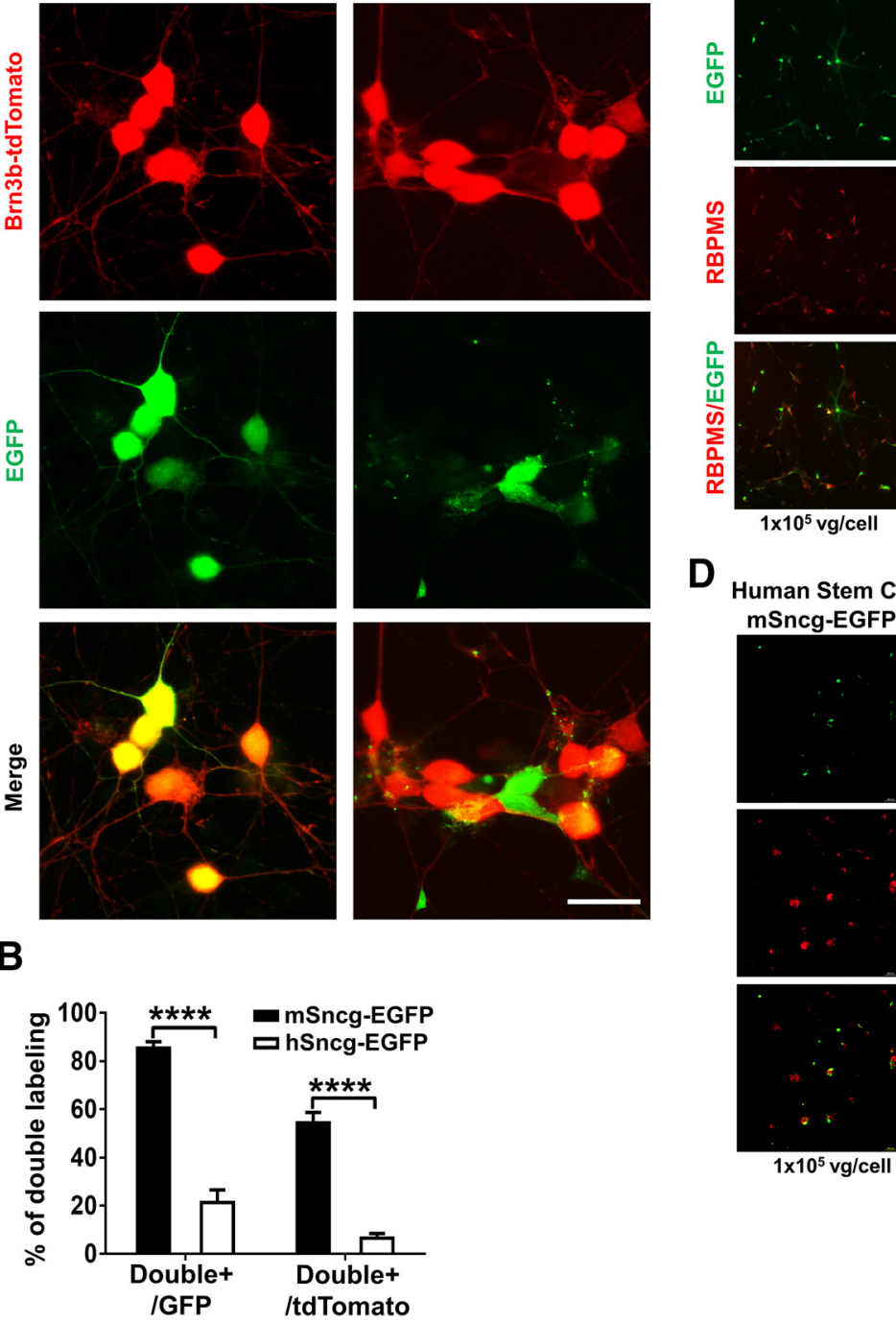

$1 \times 10^{5} \mathrm{vg} / \mathrm{cell}$

C Human primary RGCs mSncg-EGFP hSncg-EGFP
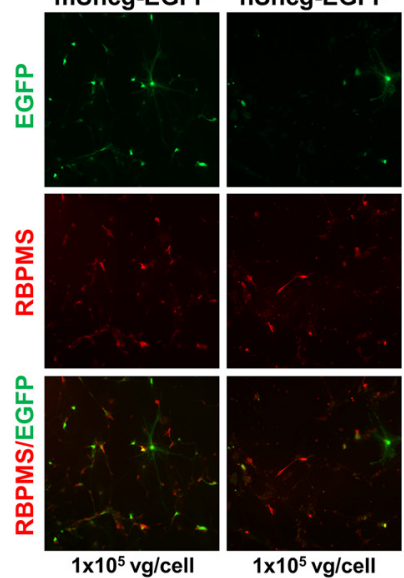

\section{D}

Human Stem Cell-derived RGCs mSncg-EGFP hSncg-EGFP
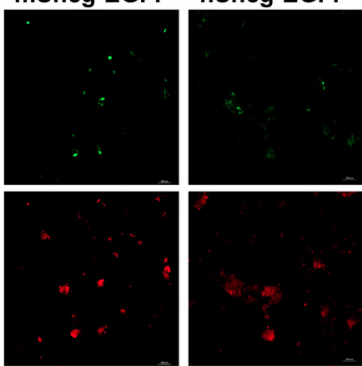

Figure 3. Co-labeling AAV-mSncg-EGFP infected hPSC-derived human RGCs with RGC reporter Brn3b-tdTomato. $A$, Confocal images of cultured hPSC-RGCs showing EGFP ${ }^{+}$and tdTomato ${ }^{+}$RGCs. Scale bar, $20 \mu \mathrm{m}$. $\boldsymbol{B}$, Quantification of EGFP/tdTomato of human primary RGCs infected with AAV-mSncg-EGFP or AAV-hSncg-EGFP at the same ratio. $\boldsymbol{D}$, Epi-fluorescence images of human stem cell-derived RGCs infected with AAV-mSncg-EGFP or AAV-hSncg-EGFP at different ratio. Scale bar, $50 \mu \mathrm{m}$.

ferentiation, BRN3b:tdTomato-expressing retinal organoids were dissociated to a single cell suspension using Accutase for $20 \mathrm{~min}$ at $37^{\circ} \mathrm{C}$. For purification of RGCs, dissociated cells were immunopurified for the cell surface receptor Thy1.2 using the magnetic-activated cell sorting (MACs) kit from Miltenyi Biotec. In brief, dissociated cells were incubated for $15 \mathrm{~min}$ at $4^{\circ} \mathrm{C}$ in the dark with $10 \mu \mathrm{l}$ of CD 90.2 beads and 90 $\mu \mathrm{l}$ of MACs buffer per 10 million cells. Subsequently, the cell suspension was run through a magnetic sorting column, followed by three PBS washes. Purified RGCs were then plated on poly-D-ornithine and laminin-coated coverslips at a density of 10,000 cells/coverslip and maintained in BrainPhys neuronal medium (STEMCELL Technologies), as previously described (Fligor et al., 2018).

\section{Isolation of human primary RGCs}

RGC isolations were performed as previously shown by Barres et al. (1988), with slight modifications to accommodate human tissue. Briefly, retinas were isolated from healthy donor eyes (within $24 \mathrm{~h}$ postmortem, six-month-old infant) by circumferential dissection at the limbus, and separation of the anterior and posterior segment of the globe. The vitreous and lens were then carefully dissected away from the retina, care was 
A
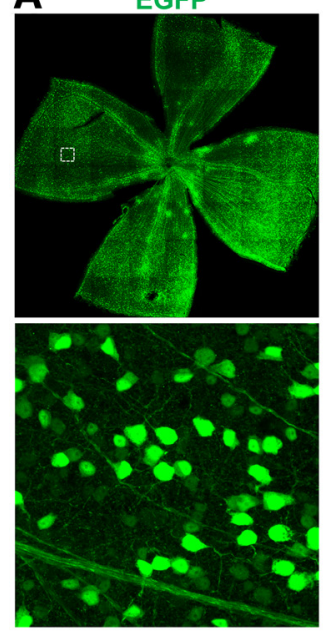

C
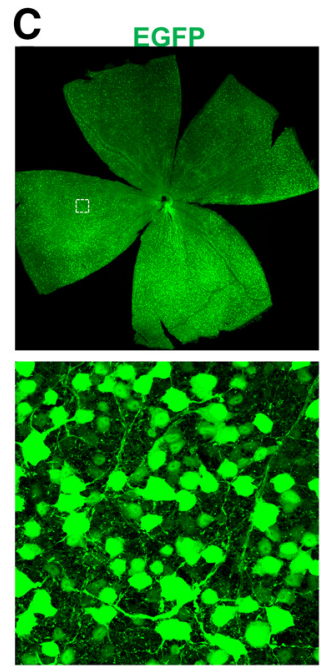

RBPMS
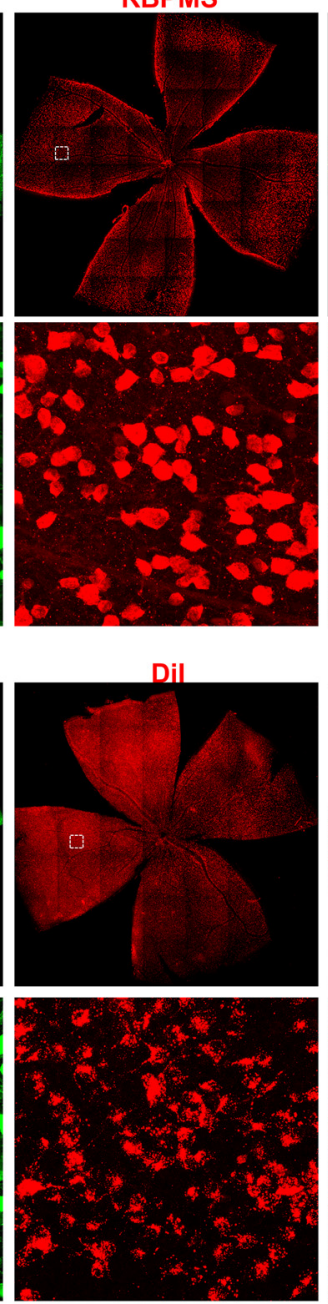
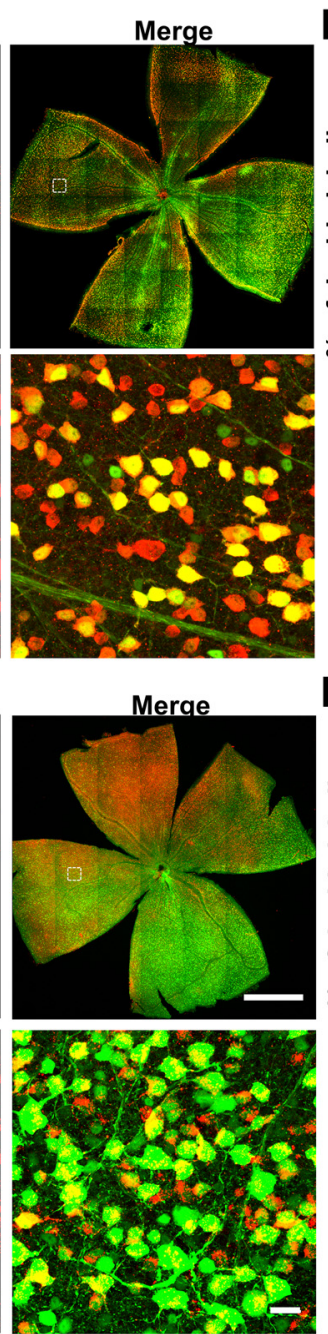

B
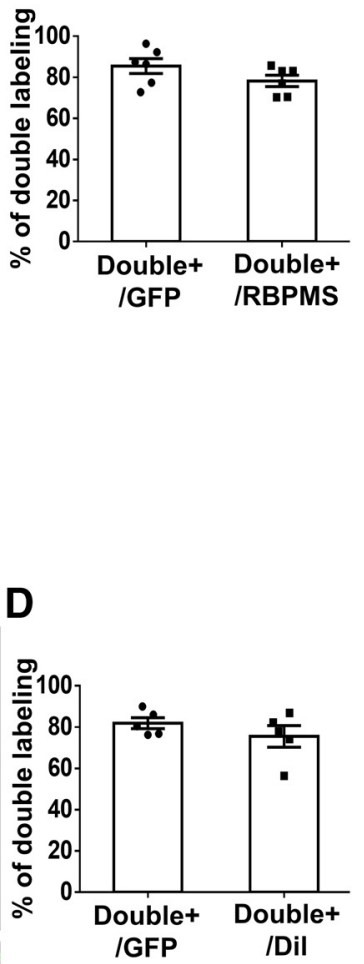

Figure 4. Co-labeling AAV-mSncg-EGFP infected cells in mouse retina with RGC markers, RBPMS or retrograde tracing dye Dil. $A$, Confocal images of wholemount retina showing EGFP ${ }^{+}$and RBPMS $^{+}$RGCS. B, Quantification of EGFP/RBPMS double-positive cells in retina. Data are presented as mean \pm SEM, $n=6$. C, Confocal images of wholemount retina showing EGFP ${ }^{+}$and $\mathrm{Dil}^{+} \mathrm{RGCS}$. Scale bar for the whole-retina images, $1 \mathrm{~mm}$. Scale bar for the enlarged white dotted square regions, $20 \mu \mathrm{m}$. $\boldsymbol{D}$, Quantification of EGFP/Dil double-positive cells in retina. Data are presented as mean \pm SEM, $n=5$.

taken to avoid retinal tearing, and retinas were separated away from the sclera. Retinas were then digested with papain to dissociate the cells. RGCs were purified from other retinal cells via a series of negative selection immuno-panning steps followed by a modified positive selection pan, using an antibody against human Thyl (Bio-Rad, F15-42-1) to select for human RGCs. RGCs were then plated on PDL+Laminin coated eight-well chamber slides (Lab-Tek; 155411) at $20 \mathrm{k}$ per well. We added the AAV at $1 \times 105 \mathrm{vg} / \mathrm{cell}$ in the culture and refreshed culture medium every other day for $5 \mathrm{~d}$ before fixation with $4 \%$ PFA in PBS and immunostaining with primary antibodies (RBPMS 1:4000) and EGFP antibody (Aves Lab, 1:200) overnight at $4^{\circ} \mathrm{C}$ and washing three times for 30 min each with PBS. The cells were incubated with secondary antibodies (1:200; Jackson ImmunoResearch) for $1 \mathrm{~h}$ at room temperature.

\section{Human embryonic stem cell culture and RGC differentiation}

Human embryonic (A81-H7) stem cells (Sluch et al., 2015) were cultured in mTeSR1 (STEMCELL Technologies), incubated at $37^{\circ} \mathrm{C}$ in $5 \%$ $\mathrm{CO}_{2}$. For RGC-like cell differentiation, we used the chemical-based protocol for neural differentiation that was previously described (Venugopalan et al., 2016). Briefly, stem cells were cultured in six-well plates to $80 \%$ confluence, then medium was changed to N2 medium (DMEM/F-12; Thermo Fischer Scientific) supplemented with 1\% N2 (Thermo Fisher Scientific) on day 0. On day 1, medium was replaced with N2 medium supplemented with dorsomorphin (1 $\mu \mathrm{M}$, Tocris), SB431542 (10 $\mu \mathrm{M}$, Sigma-Aldrich), and IWP (2 $\mu \mathrm{M}$, Sigma-Aldrich), which we named N2+Dor+SB+IWP2 (N2DSI). On day 2, to create embryonic bodies (EBs), we washed cells with PBS (without $\mathrm{Ca}^{2+}$ / $\mathrm{Mg}^{2+}$ ) for $5 \mathrm{~min}$ at $37^{\circ} \mathrm{C}$. Cells were then scraped in N2DSI medium and transferred to ultra-low attachment plates (Corning). Starting from day 3 , we changed the N2DSI medium every other day, using a cell strainer to avoid the loss of EBs, until day 9. On day 10, EBs were dissociated with Accutase (Innovative Cell Technologies) and cultured on Matrigel-coated plates using NBF medium (DMEM/F-12 supplemented with $1 \% \mathrm{PS}, 0.5 \% \mathrm{~N} 2,1 \% \mathrm{~B} 27$, and bFGF, $20 \mathrm{ng} \mathrm{ml}^{-1}$ ). Neural rosettes formed from EBs in the next $6 \mathrm{~d}$. When neural rosettes appeared, they were manually picked up with a needle, dissociated with Accutase and cultured on PDL/Laminin-coated plates using NBF medium. Neural progenitor cells (NPCs) were purified after a few passages and Rock inhibitor (Y-27632, EMD Millipore) was added for sub-culturing. RGCs were then differentiated from NPCs using Full Sato (FS) medium, which contained $10 \mu \mathrm{M} \quad \gamma$-secretase inhibitor (Notch signaling inhibitor; DAPT; EMD Millipore). Half of the medium was changed every other day until harvesting.

\section{Wholemount ON imaging}

The ON was isolated from 4\% PFA perfused mouse and imaged immediately by epi-fluorescence microscopy (Leica M165FC) or mounted on 
A
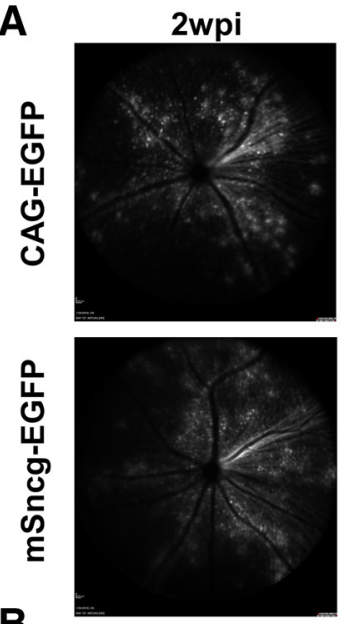

B

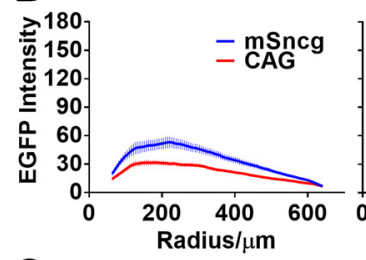

C
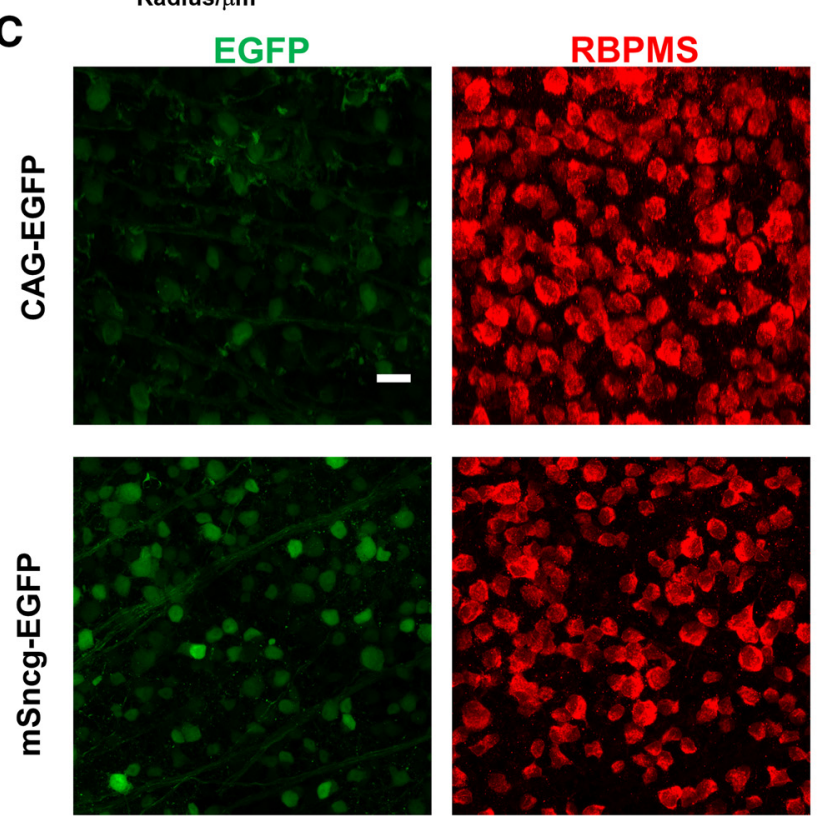

$8 w p i$
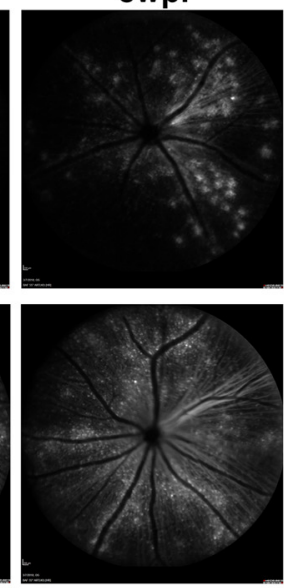

$3 \mathrm{mpi}$
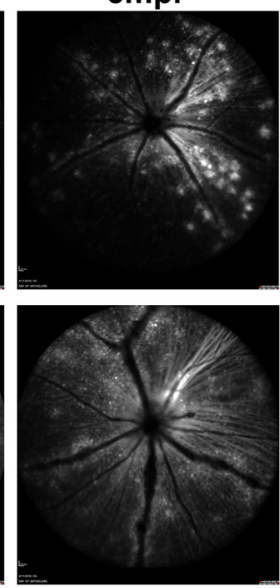

$6 \mathrm{mpi}$
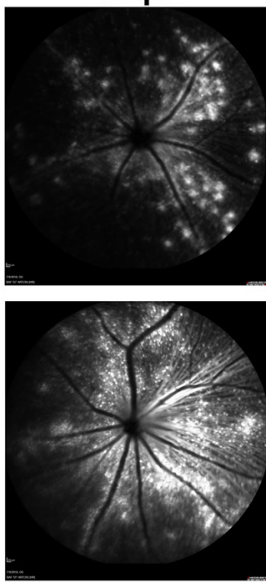

$12 \mathrm{mpi}$
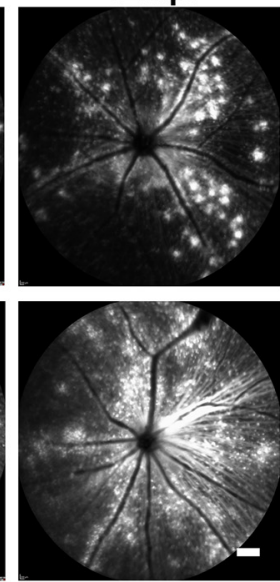

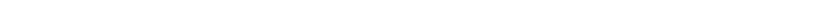

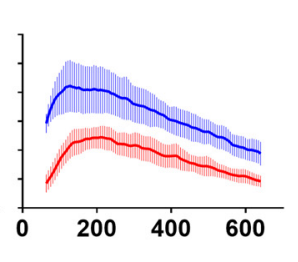
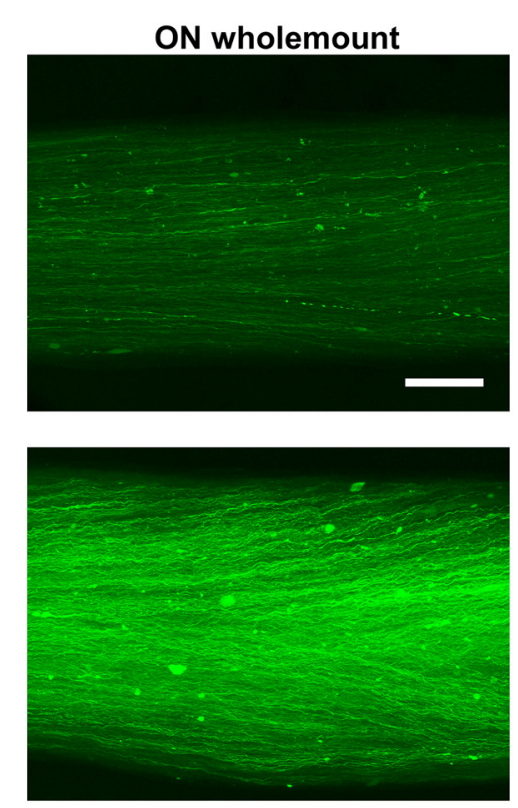

Figure 5. Long-term EGFP expression driven by mSncg or CAG promoters in mouse RGCs. $A$, Live SLO retina fundus images showing EGFP expression in RGCs at different time points after AAV intravitreal injection. Scale bar, $100 \mu \mathrm{m}$. B, Quantification of EGFP fluorescence intensities at different time points after AAV intravitreal injection. Data are presented as mean \pm SEM, $n=5-12$. C, Confocal images of retina and ON wholemounts at $12 \mathrm{mpi}$ (one year) showing EGFP+ RGC somata and axons. Scale bar of retina, $20 \mu \mathrm{m}$. Scale bar of $0 \mathrm{~N}, 100 \mu \mathrm{m}$.

a slide with Fluoromount-G and cover glass, and pressed with a $100 \mathrm{~g}$ weight scale for at least $4 \mathrm{~h}$ before imaging with a $40 \times$ lens by laser scanning confocal microscopy (Zeiss, LSCM880).

Constructs for Cas 9 and sgRNAs

The plasmid containing SpCas9 with N-terminal HA tag was purchased from Addgene (PX551, plasmid \#60957). For constructing the vector carrying SpCas9 with mSncg-0.27K promoter, the PX551 was digested with XbaI and AgeI to remove the original Mecp2 promoter. The promoter insert was amplified using the following primers: ITR-mSncg0.27K-F: catcactaggggttcctgcggcctctagaaagagtcagcagggcagaatagagc; Cas9mSncg-R: acatcgtatgggtacatggtggcgaccggtcttgaagacgtccatggtgtttgc. The backbone and insert were assembled together by Gibson reaction (NEB, E2611L).
For single guide RNA (gRNA) selection to mouse Ddit3 and Sarm1 genes, the 20-nt target sequences were selected to precede a $5^{\prime}$-NGG protospacer-adjacent motif (PAM) sequence in the coding exons (https:// portals.broadinstitute.org/gpp/public/analysis-tools/sgrna-design). For each gRNA, two partially complementary oligos with 4 nt overhangs compatible for cloning were synthesized and annealed and ligated into SapI digested PX552 vector (Addgene, plasmid \#60958) that carries the gRNA scaffold with U6 promoter. The original PX552 plasmid was used as control (control gRNA). For the multiplex gene targeting strategy, individual gRNA cassettes with U6 promoter and gRNA scaffold were pasted into the region between ITR and until four U6-sgRNA cassettes were built into one construct. All obtained constructs were verified by sequencing.

In order to select sgRNAs that knock-down mouse Ddit3 and Sarm1 more efficiently in vitro, we subcloned Ddit3 and Sarm1 with fused 

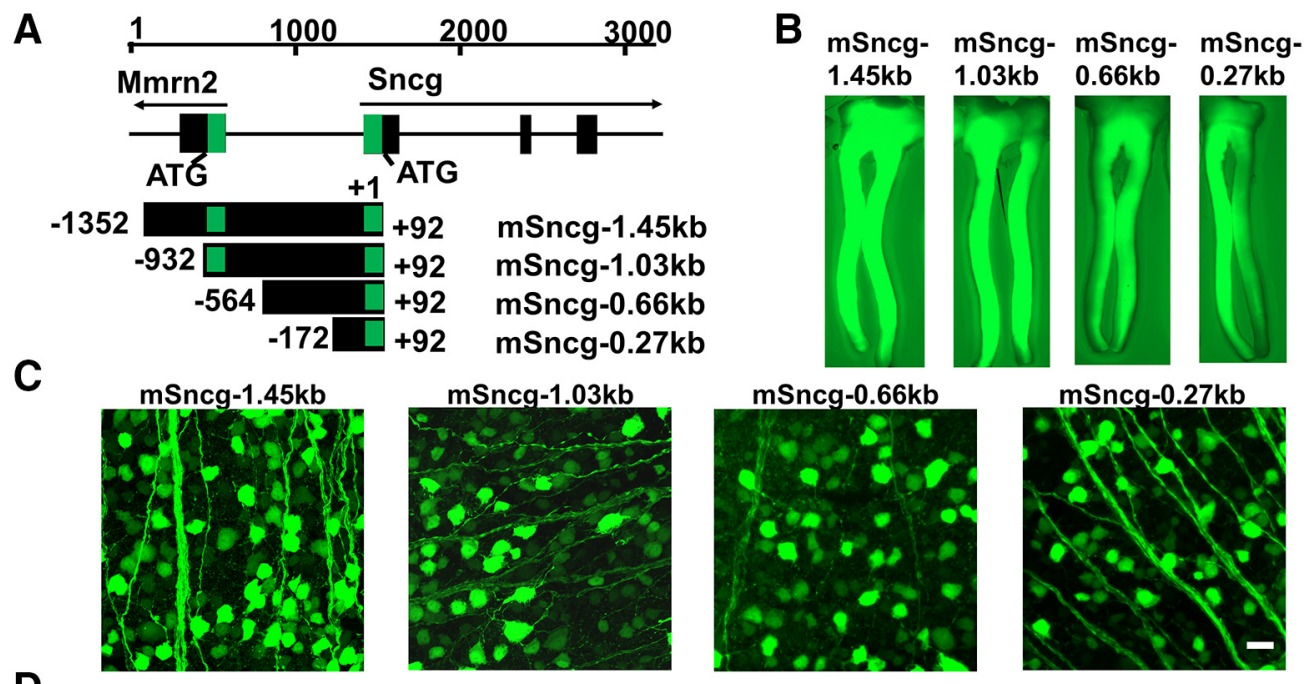

mSncg- $0.66 \mathrm{~kb}$
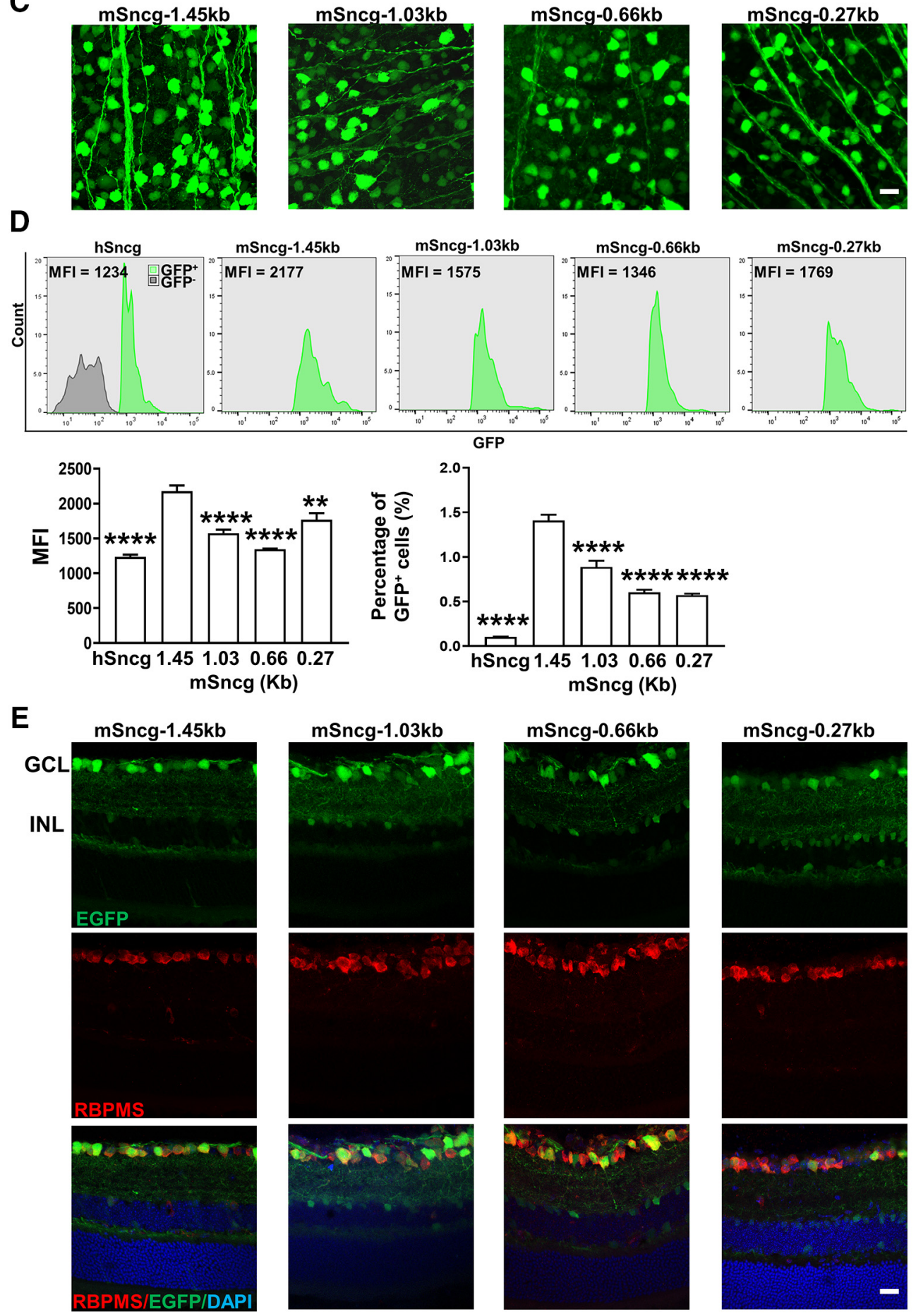

Figure 6. The specificity and potency of different truncated forms of mSncg promoter in mouse RGCs. A, Schematic illustration of the mouse Sncg gene and its promoters. The Sncg gene is located on chromosome 14 (34370274-34374669) adjacent to multimerine 2 gene (Mmrn2). The 1.45-kb mSncg promoter starts from - 1352 bp upstream of + 1 Sncg transcription start site and ends at $+92 \mathrm{bp}$. It includes partial sequence of the first intron and the whole first exon of Mmrn2, the non- transcription regions between Mmrn2 and mSncg genes, and the non-translated region of the first exon of mSncg. The green "boxes" represent non-translated regions. B, Epi-fluorescence low-magnification images of ON wholemounts showing EGFP expression in RGC 


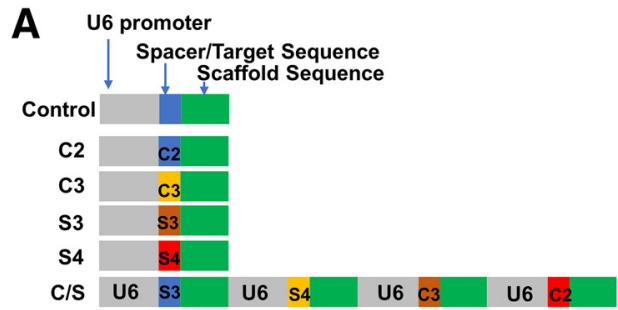

\begin{tabular}{l|l}
\hline Control GGAAGAGCGAGCTCTTCT \\
C1 & GGTGCCCCCAATTCATCTG \\
C2 & GTCCCTAGCTTGGCTGACAG \\
C3 & GACTGGAATCTGGAGAGCGA \\
C4 & GTCAGAGTTCTATGGCCCAGG \\
& \\
S1 & GGTGTTGGCTACCAACAAGG \\
S2 & GCATTCGTAGAGTAAGAAACC \\
S3 & GCTAGACCGATGCGCCCACG \\
S4 & GACCAGTACAGCACCGCGTCG
\end{tabular}
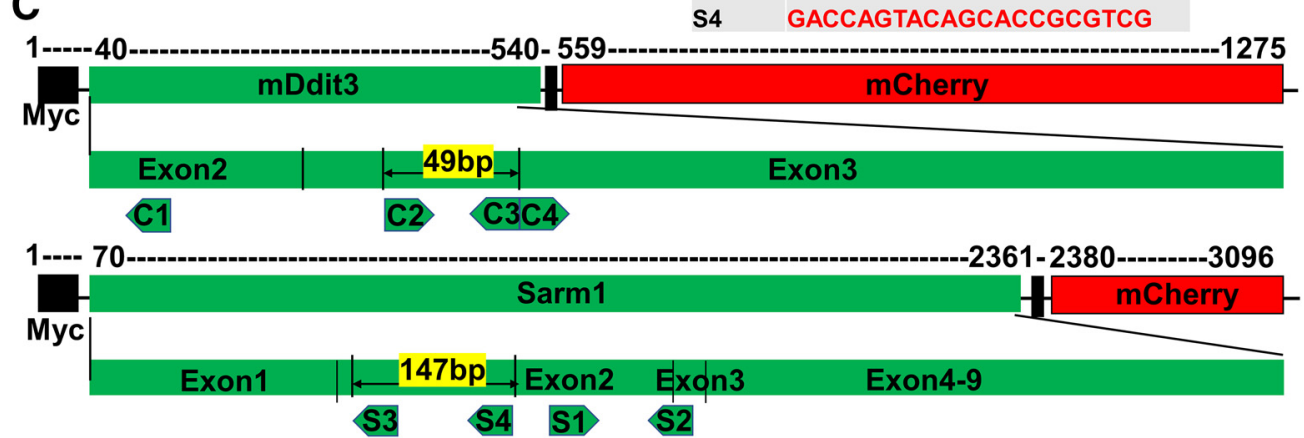

D CMV-SpCas9/gRNA/Ddit3 or Sarm1-mCherry co-transfection in HEK293T

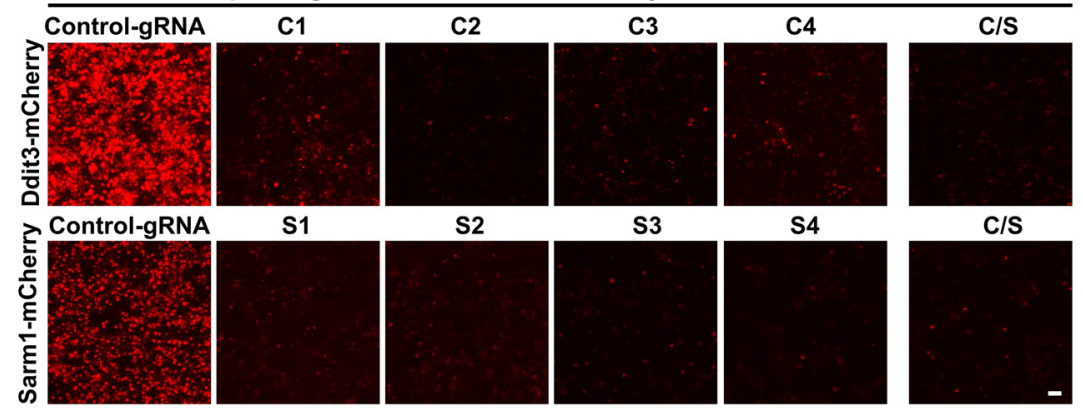

Figure 7. In vitro assays to select effective Ddit3 and Sarm1 gRNAs. A, Schematic illustration of AAV vectors for U6 promoter driven gRNA expression. The C/S gRNAs include four U6 promoters that drive 2 Ddit3 and Sarm 1 gRNAs individually. B, Sequences of 4 Ddit3 gRNAs and Sarm 1 gRNAs that we tested in vitro. The red coded sequences are selected to make C/S gRNAs. C, Schematic illustration of mCHOP-mCherry and Sarm1-mCherry constructs and corresponding targeting regions of gRNAs. Note, 49 bp in between of C2 and C3 sgRNAs and 147 bp in between of S3 and S4 sgRNAs are potential truncations by paired sgRNAs. D, Co-transfection of SpCas9, gRNAs and reporters (Ddit3-mCherry or Sarm1-mCherry) in HEK293T cells to determine knockdown effects. Scale bar, $50 \mu \mathrm{m}$.

mCherry into AAV vectors to overexpress both genes. mDdit3 was amplified from Addgene plasmid \#21913 using the primer pair: mDdit3F: gcggccgcacgcgtctcgagaattcatggagcaaaagctgatttctgaggagg and mDdit3mCherry-R: cttgctcacagctccacctccacctcctgcttggtgcaggctgaccatgcgg; mCherry was amplified with mDdit3-mCherry-F: ccgcatggtcagcctgcaccaagcaggaggtg gaggtggagctgtgagcaag and mCherry-R: cagaggttgattatcgataagcttctcgactagtttccggacttgtacagctc. The two fragments were assembled to a pAM backbone that cut from pAM-AAV-CAG-EGFP-WPRE with EcoRI and MluI. mSarm1 was amplified from Addgene plasmid \#50707 using mSarm1-F: gcggccgcacgcgtctcgagaattcatgGAGCAAAAGCTGATATCTGAAGAGGAC and mSarm 1-mCherry-R: cttgctcacagctccacctccacctccaggcagacccattggcgtagctccc. mCherry was amplified with mSarm 1-mCherry-F: gggagctacgccaatgggtctgcctggaggtggaggtggagctgtgagcaag and mCherry-R: cagaggttg attatcgataagcttctcgactagtttccggacttgtacagctc.

\section{$\leftarrow$}

axons. C, Confocal images of wholemount retinas showing EGFP-positive RGCS. Scale bar, 20 $\mu \mathrm{m}$. D. The MFI and percentage of GFP+ cells of each promoter-driven GFP among total retina cells were measured by FACS. Data are presented as mean \pm SEM, $n=4$; ${ }^{* *} p<0.01,{ }^{* * *} p<0.0001$; one-way ANOVA with Tukey's post hoc test. $\boldsymbol{E}$, Confocal images of cross sections of retinas showing EGFP signals in different retina layers. Scale bar, $20 \mu \mathrm{m}$.
Live retina fundus imaging with scanning laser ophthalmoscopy (SLO) After the mice were anesthetized, pupils were dilated by applying $1 \%$ tropicamide sterile ophthalmic solution (Akorn), and the customized $+10 \mathrm{D}$ contact lens (3.0-mm diameter, 1.6-mm BC, PMMA clear, Advanced Vision Technologies) applied to the dilated pupil. The retina fundus images were captured with the Heidelberg Spectralis SLO/OCT system (Heidelberg Engineering) equipped with 488 excitation laser and $55^{\circ}$ noncontact lens. The focal point position to the ON head, imaging area and mouse position were fixed for every animal for reliable comparison. The fluorescent fundus images were acquired at 70 sensitivity, high-resolution mode, and 30 frames average. To determine the GFP intensity on fundus images, the fluorescence intensity to radius measurement with the center at the optic disk was obtained by ImageJ and the Concentric Circles Plugin as described before (Wassmer et al., 2017).

Spectral-domain optical coherence tomography (SD-OCT) imaging The animal anesthesia, pupil dilation, contact lens application, and mouse position were the same as for SLO imaging, except that a $30^{\circ}$ lens (Heidelberg Engineering) was used. The Spectralis OCT has an $870-\mathrm{nm}$ infrared wavelength light source, and the scanner has $7-\mu \mathrm{m}$ optical axial resolution, $3.5-\mu \mathrm{m}$ digital resolution, and $1.8-\mathrm{mm}$ scan depth at $40-\mathrm{kHz}$ scan rate. The mouse retina was scanned with the ring scan mode centered by the $\mathrm{ON}$ head at 100 frames average under high-resolution mode (each B-scan consisted of 1536 A scans). The scanning ring has a fixed 
A mSncg-0.27kb-HA-SpCas9

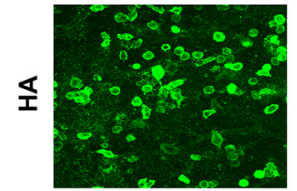

GFP

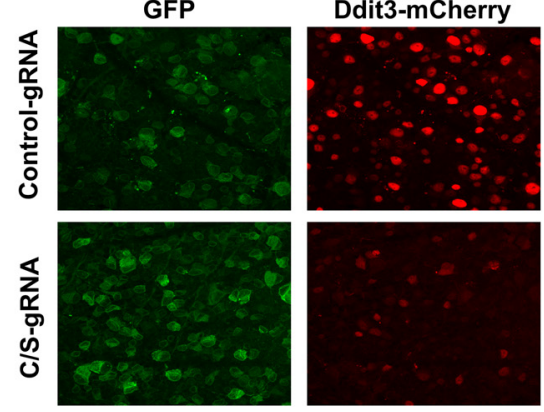

C
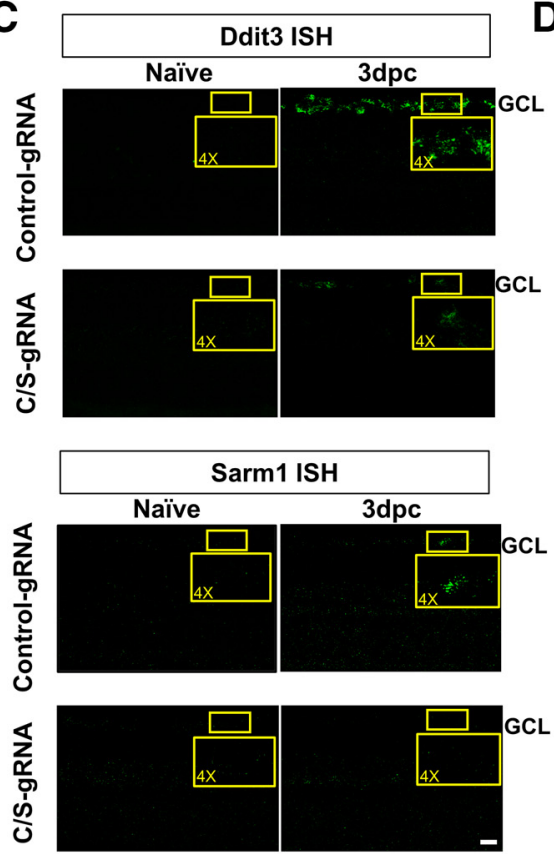

B mSncg-Cre in LSL-Flag-SpCas9

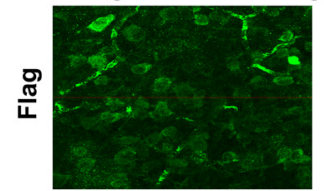

GFP

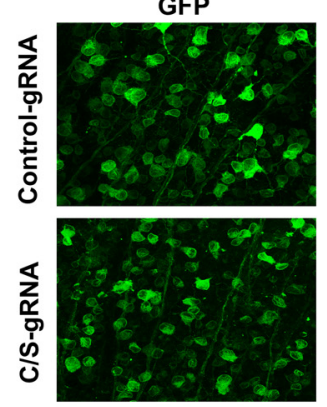

D
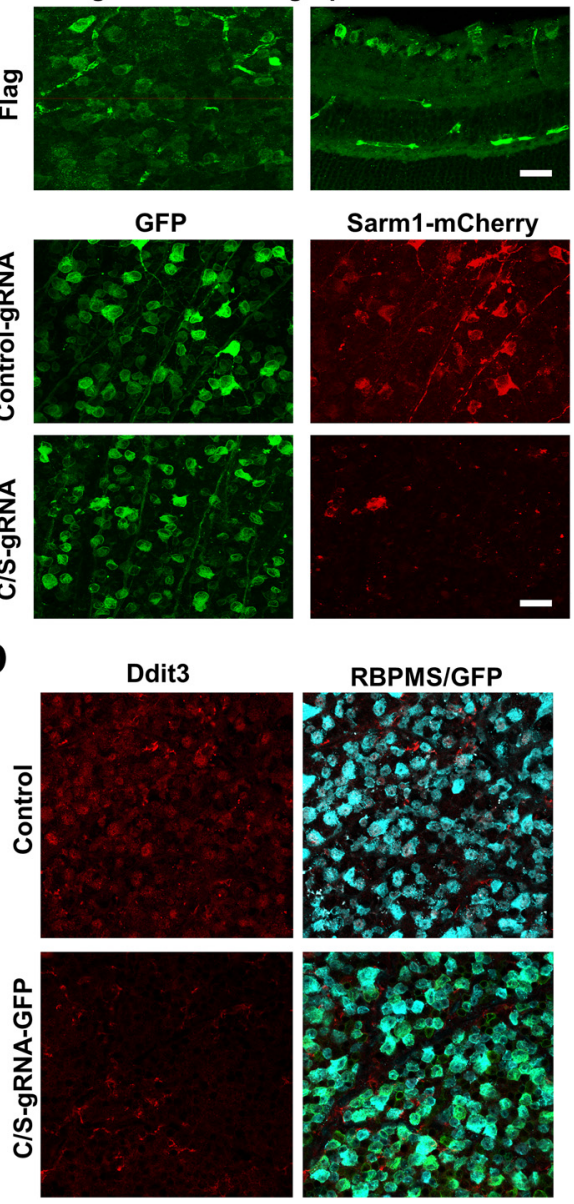

Sarm1-mCherry
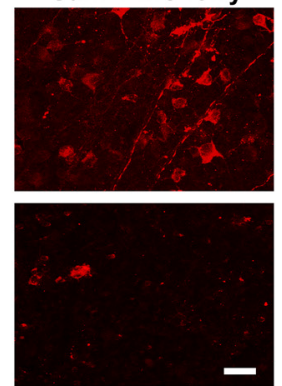

RBPMS/GFP
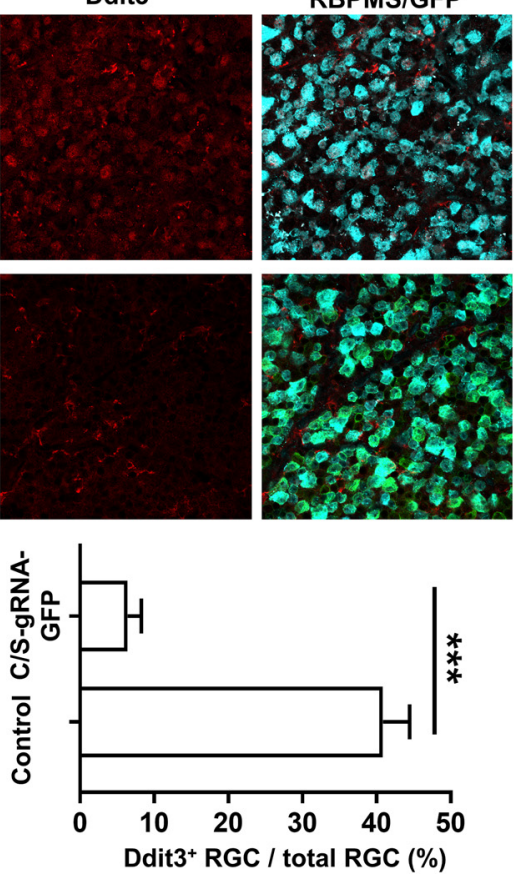

Figure 8. Ddit3 and Sarm1 knock-down by AAV-mSncg-CRISPR/Cas9 in mouse RGCs. A, Confocal images of wholemount retinas showing AAV-mSncg-HA-SpCas9 expression in retina (upper panel) and the expression of C/S gRNAs-GFP in RGCS (GFP-positive cells) and Ddit3-mCherry inhibition. $\boldsymbol{B}$, Confocal images of wholemount retinas showing AAV-mSncg-Cre-mediated FlagSpCas9 expression in retinas of LSL-Flag-SpCas9 mice, and Sarm1-mCherry inhibition by C/S gRNAs-GFP. Scale bar, $20 \mu \mathrm{m}$. C, Confocal images of cross sections of retinas showing Ddit3 and Sarm1 mRNA levels in GCL by ISH. Scale bar, $20 \mu \mathrm{m}$. D, Confocal images of wholemount retinas showing Ddit3 expression in RGCs. For Ddit3-positive RGCs counting, four random fields from each retina were imaged using a $40 \times$ oil lens, and the RGCs doubly positive for RBPMS and Ddit3 were counted by masked observer. The percentage of Ddit3 + RGCs was calculated as the ratio of Ddit3 + RGCs compared with total RGCs in the field. Data are presented as mean \pm SEM, $n=5 ;{ }^{* * *} p<0.001$, Student's $t$ test.

diameter of $160 \mu \mathrm{m}$, and we fixed the focal length at scale 37D. We always placed the $\mathrm{ON}$ head in the center of the ring, which allowed us to scan the same area and same distance from the ON head to the ring of each eye. The GCC thickness was determined by averaging the GCC thickness along the whole parameter of the ring, not in a specific direction. The GCC includes retinal nerve fiber layer (RNFL), ganglion cell layer (GCL), and inner plexiform layer (IPL). The average thickness of GCC around the ON head was measured manually with the aid of Heidelberg software. The mean of the GCC thickness in the injured retina was compared with that in the contralateral control retina to yield a percentage of GCC thickness value. The investigators who measured the thickness of GCC were blinded to the treatment of the samples.
Off-target of gRNA analysis

To find the predictive off-targets, we used the online CRISPR RGEN Tool, Cas-OFFinder, based on two criteria. First, potential off-targets can have a maximum of two mismatches with the gRNA (Hsu et al., 2013). Second, potential off-targets must match perfectly in their seed (12 nt $3^{\prime}$ of the PAM sequence) with a maximum of two mismatches in the rest of the gRNA (Cong et al., 2013). Using these criteria, we could not detect off-target for any of the gRNAs that we used, except one Ddit3 gRNA (GACTGGAATCTGGAG AGCGA), which has one off-target with three mismatches (GtgTGtAATCTGGAG AGCGAGGG). The activity of the off-target was evaluated by surveyor assay.

\section{RGC purification by FACS}

Five weeks after intravitreal injection of AAV-C/S gRNAs-hSyn1-GFP and AAV$0.27 \mathrm{k}$ mSncg-HA-SpCas9, retinas were collected after sacrifice. The retinal cells were dissociated by a neuron dissociation kit (FUJIFILM Wako Pure Chemical Corporation) following the manufacturer's instruction. The cells were resuspended in PBS and filtered by $40-\mu \mathrm{m}$ cell strainer (Corning) for FACS. GFP+ cells were collected by FACS (FACSAria Fusion Sorter, BD Biosciences). gDNA was isolated from collected cells using QIAamp DNA Mini kit (QIAGEN).

Quantification of the median fluorescence intensity (MFI) by FACS

AAV-hSncg-GFP, AAV-mSncg-1.45kb-GFP, AAV-mSncg-1.03kb-GFP, AAV-mSncg-0.66kbGFP, or AAV-mSncg-0.27kb-GFP were intravitreally injected into mice. Retinas were collected three weeks after injection and retinal cells dissociated as described above. The cells were fixed by $4 \% \mathrm{PFA}$, resuspended in PBS, and filtered by $40-\mu \mathrm{m}$ cell strainer (Corning) for FACS. Approximately $100 \mathrm{GFP}+$ cells were analyzed by FACS (LSRII- analyzer, BD Biosciences) from each sample, and each sample was acquired four times to generate the MFI, which is used to describe the brightness of GFP. MFI and percentage of GFP+ cells within the total retinal cells were calculated by FlowJo_v10.

\section{Genomic deletions analysis}

Paired sgRNAs were designed to maximize the efficiency of editing the target genes, which can also result in genomic deletions. For the analysis of deletions, the primers were designed to anneal to outside the deleted region to verify the successful deletion by product size analysis using electrophoresis in agarose gels (Ran et al., 2013).

\section{Targeted deep sequencing and data analysis}

Targeted deep sequencing primers were designed to amplify 100-200 bp on either side of the gRNAs' targets (for a total amplicon $500 \mathrm{bp}$ long) with generic adapters. Ddit3-F, acactctttccctacacgacgctcttccgatctGTC AAGTATAGGCAAGAGGC; Ddit3-R, gactggagttcagacgtgtgctcttccgatct TTGAGCCGCTCGTTCTCTTCA; Sarm1-F, acactctttccctacacgacgctc ttccgatctTTCTGTCTGCCATGACTCAC; Sarm1-R, gactggagttcagacgt gtgctcttccgatctTTCCACCTCCTTGTTGGTAG. Low-cycle PCR was 


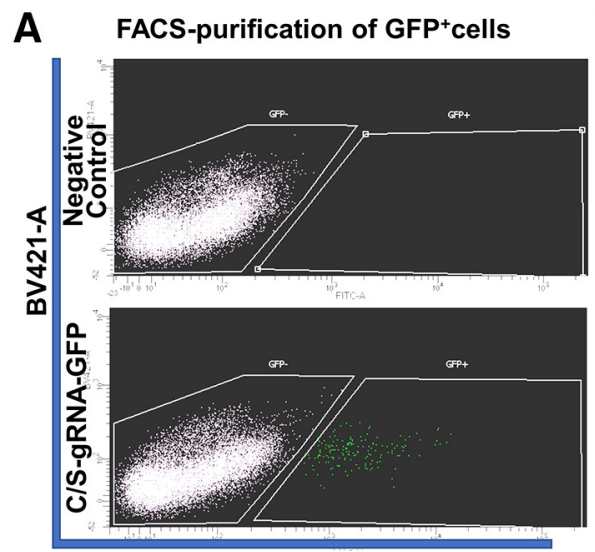

FITC-A

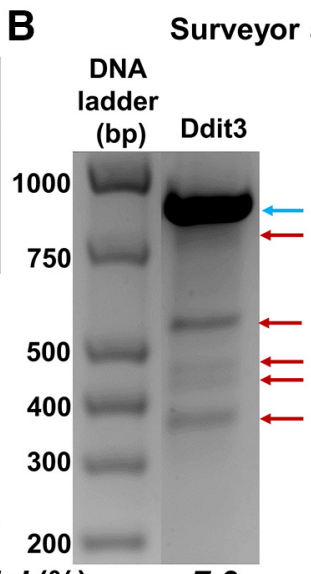

Indel (\%)
7.3
DNays of $\mathrm{GFP}^{+}$cells
DNA

ladder

(bp) Sarm1

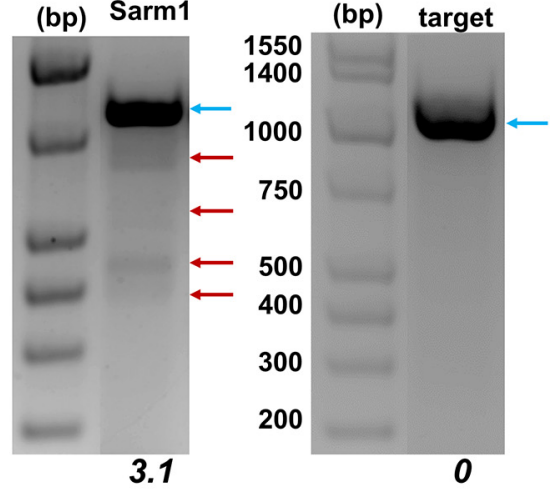

C Double gRNAs deletion in GFP+ RGCs

DNA

ladder

(bp)

Ddit3

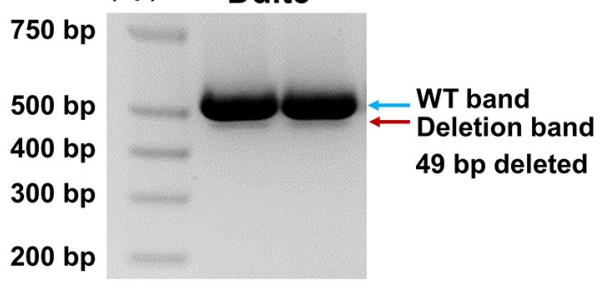

DNA
ladder

(bp) Sarm1

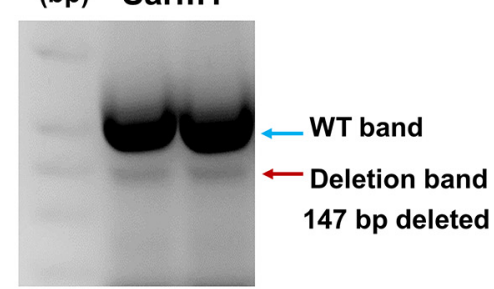

D

\section{Targeted deep-sequencing of $\mathrm{GFP}^{+} \mathrm{RGCs}$}

Ddit3
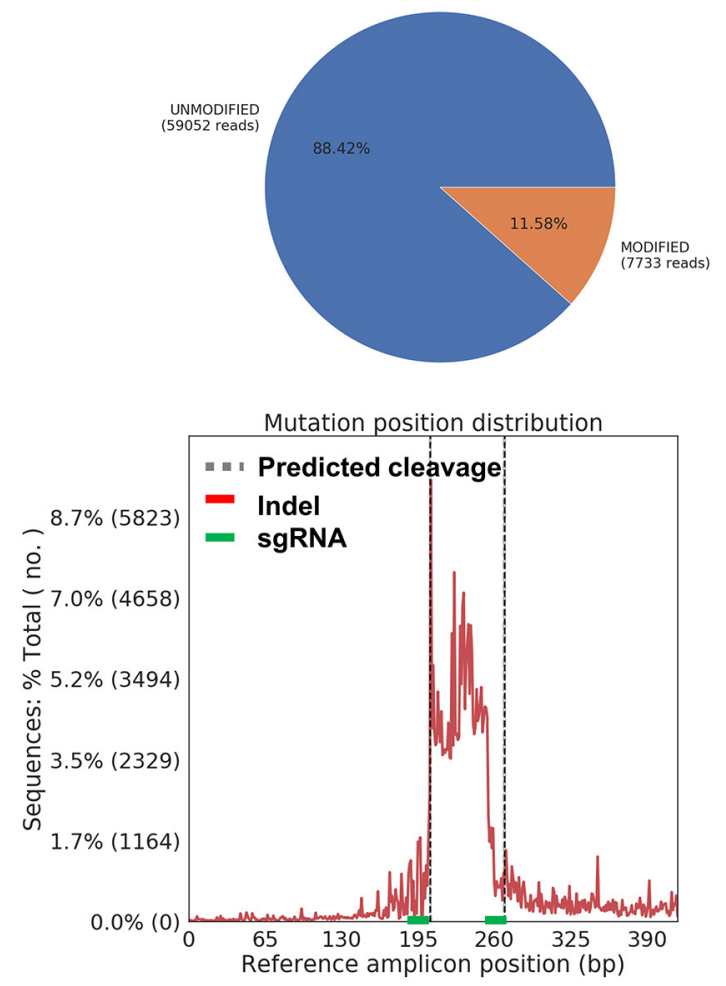

Sarm1
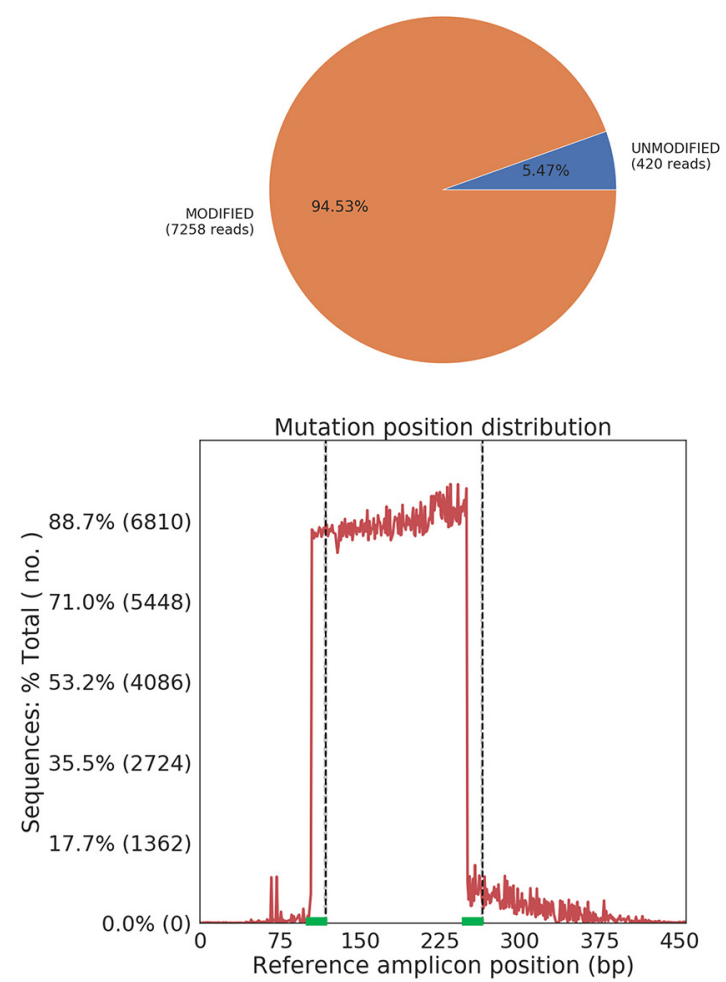

Figure 9. The efficiencies of Ddit3 and Sarm1 genomic editing in mouse retina by AAV-mediated CRISPR/Cas9. AAV-Sncg-Cas9 and AAV-U6-C/S gRNAs-Syn1-GFP were c0-injected intravitreally. A, Representative FACS plots of dissociated retinal cells gated for GFP+ cell isolation. BV421 (405 nm violet laser channel) was used to gate autofluorescence and FITC channel was used to gate GFP + cells. A total of 10 WT mice were intravitreally injected with $6 \times 109 \mathrm{vg}$ AAV-mSncg-Cas9 and $3 \times 109 \mathrm{vg}$ AAV-C/S gRNAs-Syn1-GFP. B, Surveyor assay revealing indel formation at the Ddit3 and Sarm1 genomic locus, but not the off-target locus. Blue arrows are WT bands; red arrows are indel bands. C, Representative gel images showing WT and deletion bands 
performed using Q5 High-Fidelity DNA Polymerase (NEB). Gel purification of PCR products was by size- fractionating and the DNA was extracted using MicroElute Gel Extraction kit (Omega Bio-Tek). Samples were pooled in equal amounts and a mixed barcoded library sequenced (paired-end 250 bp) by GENEWIZ Amplicon-EZ sequencing service (GENEWIZ). More than 50,000 reads were generated with each sample using Illumina platform. Data analysis was performed with CRISPResso2 (Clement et al., 2019).

SURVEYOR nuclease assay

The amplicons were PCR-amplified from gDNA of GFP + cells collected by FACS. The primers are: Sur-Ddit3-F, CGACTGTGGTGAAT GGAATG; Sur-Ddit3-R, GAGACAGACAGGAGGTGATG; Sur-Sarm1F, GGGTTGAAAACATTCAACCG; Sur-Sarm1-R, GCACAGGTAGAA TGCTCCTA; Sur-off-target-F, TGGGAGATGCCTCCTCAAAC; Suroff-target-R, AGATATGCTATTTGCCACTGCC. The amplicons were then denatured at $95^{\circ} \mathrm{C}$ and gradually reannealed to allow the formation of DNA heteroduplexes. The annealed heteroduplexes were digested with SURVEYOR nuclease (Integrated DNA Technologies) following the manufacturer's instructions. The products were visualized on a $1.5 \%$ (wt/vol) agarose gel. The intensity of the bands of the PCR amplicons and cleavage products was measured by using ImageJ. The indel ratio (indel \%) was calculated using the equation below, where $a$ is the integrated intensity of the PCR amplicon and $b$ and $c$ are the integrated intensities of each cleavage product:

$$
\text { Indel } \%=100 \times(1-\sqrt{1-(b+c) /(a+b+c)})
$$

\section{P19 cell culture and transfection}

P19 cells (ATCC) were cultured at $37^{\circ} \mathrm{C}$ in a $5 \% \mathrm{CO}_{2}$ in air atmosphere in Alpha MEM (Thermo Fisher Scientific) with 5\% fetal bovine serum (Thermo Fisher Scientific), $100 \mathrm{U} / \mathrm{ml}$ penicillin and $100 \mathrm{U} / \mathrm{ml}$ streptomycin (Thermo Fisher Scientific). One day before the transfection, cells were seeded at $3 \times 105$ cells/well in six-well tissue culture plate. Transfection was performed by using TransIT-X2 transfection reagent (Mirus) following the manufacturer's instructions. Briefly, cells were $80 \%$ confluent at the time of transfection; $2.5 \mu \mathrm{g}$ total DNA plasmid $(\mathrm{C} /$ S-gRNA: Cas9 $=1: 2$ or Cas9 only as control) added in to Opti-MEM I reduced serum medium (Thermo Fisher Scientific), and then $7.5 \mu \mathrm{l}$ TransIT-X2 added into the DNA. The mixture incubated at room temperature for $20 \mathrm{~min}$ to allow complexes to form. Distributed the complexes to cells and harvest the cells $48 \mathrm{~h}$ after transfection. gDNA from the cells was isolated using QIAamp DNA Mini kit (QIAGEN). Gene editing efficiency was detected by targeted deep sequencing and SURVEYOR assay.

Statistical analyses

GraphPad Prism 6 was used to generate graphs and for statistical analyses. Data are presented as mean \pm SEM. Student's $t$ test was used for two groups comparison and one-way ANOVA with post hoc test was used for multiple comparisons.

\section{Results}

\section{AAV-mSncg promoter drives potent GFP expression in mouse RGCs after intravitreal injection}

To identify a RGC-specific promoter, we collected a group of promoters that are commonly used in AAVs to drive gene expression in neurons (CAG, mPGK, mCaMKIIa; Mayford et al., 1996; Gerits et al., 2015), SynI (Kügler et al., 2003), and predicted promoter sequences from several RGC-specific genes,

$\leftarrow$

of Ddit3 and Sarm1. Blue arrows are WT bands; red arrows are deletion bands. D, Schematic illustration of the insertion/deletion ratio and position distribution in the targeted regions of C/S gRNAs in mouse Ddit3 and Sarm 1 locus, detected by deep sequencing.
Sncg (Surguchov et al., 2001; Buckingham et al., 2008; Soto et al., 2008; Surgucheva et al., 2008), Isl2 (Pak et al., 2004), Thy1 (Vidal et al., 1990; Spanopoulou et al., 1991), Tubb3 (Mellough et al., 2004), GAP43 (Meyer et al., 1994; Schaden et al., 1994), and RBPMS (Kwong et al., 2010; Rodriguez et al., 2014). We subcloned the promoters into the same AAV2 backbone vector to drive expression of reporter gene, EGFP (Fig. 1A). We injected the same amount of AAVs into the vitreous $(3 \times 109 \mathrm{vg} /$ eye $)$ and used retinal cross sections to screen the tested promoters for cell transduction in the GCL (Fig. 1B). In dramatic contrast to the commonly used universal CAG promoter, which drives EGFP expression in both GCL and inner nuclear layer (INL), the mouse and human Sncg demonstrated the best specificity among the promoters that we tested, as evidenced by restricted EGFP in GCL (Fig. 1B,C). Isolated RBPMS-positive cells in INL that colocalize with GFP represent displaced RGCs in INL. Based on EGFP intensity as a reflection of promoter strength (Fig. 2A,C), $\mathrm{mSncg}$ promoter showed much stronger activity than any of the other promoters tested, except for mCaMKIIa promoter, which drove EGFP expression as robustly as $\mathrm{mSncg}$, but did not restrict expression to the GCL. Unexpectedly, the predicted RBPMS promoter, containing the RBPMS gDNA sequence from -1589 to +885 , did not have strong promoter activity. Interestingly, mSncg promoter was much more potent than hSncg promoter, as evidenced by stronger EGFP intensity in both wholemount retina and ON (Fig. 2A,B).

To determine the activities of human and mouse Sncg promoters in human RGCs, we tested AAV2-mSncg and hSncgEGFP in hPSC-derived RGCs (Ohlemacher et al., 2015, 2016; Sluch et al., 2017). A Brb3b:tdTomato reporter has been engineered into this hPSC line and the human RGCs derived from it are labeled with tdTomato (Fig. $3 A$ ). Surprisingly but consistent with the result from mouse retina, AAV2-mSncg-EGFP also much more efficiently targeted the majority of hPSC-derived human RGCs than AAV2-hSncg-EGFP (Fig. 3A,B). This phenotype was further confirmed in human primary RGCs and human stem cell-derived RGCs (Fig. 3C,D). Our subsequent experiments therefore focused on characterizing the mSncg promoter.

To determine the extent and specificity with which AAV2mSncg-EGFP targeted RGCs after intravitreal injection, we labeled RGCs with a pan-RGC marker, RBPMS (Kwong et al., 2010; Rodriguez et al., 2014). Approximately $78 \%$ of RBPMS ${ }^{+}$ RGCs were double labeled with GFP, and $\sim 85 \%$ of $\mathrm{GFP}^{+}$cells were double labeled with RBPMS (Fig. $4 A, B$ ), indicating that AAV2-mSncg-EGFP efficiently targeted the majority of RGCs and that most of the cells transduced by AAV2-mSncg-EGFP were RGCs. Since $>85 \%$ of mouse RGCs project their axons to SC (Ellis et al., 2016), we also injected neuronal tracing dye DiI into SC to retrogradely label the majority of RGCs. Again, $\sim 75 \%$ of $\mathrm{DiI}^{+}$RGCs were double labeled with GFP, and $\sim 82 \% \mathrm{GFP}^{+}$ RGCs were also labeled with DiI (Fig. 4C,D). Considering that none of these confirmatory methods label all RGCs, these results increased confidence that AAV2-mSncg-EGFP effectively targeted a large majority of RGCs in vivo.

\section{AAV2-mediated transgene expression follows a unique dynamic long-term pattern in mouse RGCs}

AAV rarely integrates into the host genome, and instead remains as episomes that express transgenes for a long period of time (Schnepp et al., 2003; Hastie and Samulski, 2015). To determine its expression pattern in RGCs, we injected AAV2-mSncg-EGFP and AAV2-CAG-EGFP intravitreally into two groups of mice and used live fundus imaging with SLO to monitor EGFP 
expression in retina. Consistent with our histologic studies, $\mathrm{mSncg}$ promoter drove transgene expression much more potently than CAG promoter at all time points after AAV injection (Fig. 5A,B). However, both promoters showed similar dynamic expression patterns: expression peaked at four weeks post injection (wpi), decreased for several weeks thereafter, and then steadily recovered from three months postinjection (mpi) to $12 \mathrm{mpi}$ (the latest time point that we studied). Similar dynamic changes of AAV-mediated gene expression have also been seen in blood and liver cells, the immune responses seem playing an important role (Nathwani et al., 2002; Sabatino et al., 2007, 2011; Favaro et al., 2011). Wholemounts of retinas and $\mathrm{ON}$ at $12 \mathrm{mpi}$ confirmed potent long-term expression of EGFP in RGCs (Fig. 5C). In summary, mSncg promoter can drive long-term transgene expression in RGCs.

\section{Truncated forms of mSncg promoter maintain strong promoter activities but decrease RGC specificity}

The capacity of the AAV vector is $\sim 4.7$ kilo base pairs $(\mathrm{kb})$ in between two inverted terminal repeats (ITRs); a shorter promoter will allow larger transgene packaging. We truncated the $1.45-\mathrm{kb}$ $\mathrm{mSncg}$ promoter that we originally tested from upstream $\left(5^{\prime}-\right)$ into three different sizes, $1.03,0.66$, and $0.27 \mathrm{~kb}$ (Fig. 6A). Wholemounts of $\mathrm{ON}$ and retinas and FACS analysis of dissociated retinal cells demonstrated that all of these truncated forms of mSncg promoter drove comparable EGFP expression in RGCs although to a lesser degree than the full-length $\mathrm{mSncg}$ promoter (Fig. $6 B-D$ ), and therefore that they retained the core promoter region. However, retinal cross sections revealed increasing INL cell labeling with increasing truncation, and therefore a noticeable decline in the RGC specificity (Fig. 6E). These data suggest that upstream regions of the $\mathrm{mSncg}$ promoter contain cis-regulatory elements important for RGC specificity.

\section{AAV-mSncg promoter-mediated CRISPR/Cas9 efficiently knocks down Ddit3 and Sarm1 in mouse RGCs}

We previously found that $\mathrm{ON}$ injury induces endoplasmic reticulum (ER) stress in RGCs (Hu et al., 2012). ER stress activates a complex cascade of reactions, in general called the unfolded protein response (UPR; Wang and Kaufman, 2016). We further demonstrated that deletion of Ddit3, one of the critical UPR genes that mediates ER stress-induced apoptosis, preserve the structure and function of both RGC somata and axons in experimental ON crush, glaucoma and EAE/optic neuritis (Hu et al., 2012; Yang et al., 2016a; Huang et al., 2017). Because neuronal soma and axon degenerations are active autonomous processes with distinct molecular mechanisms (Wang et al., 2012; Howell et al., 2013; Conforti et al., 2014; Gerdts et al., 2016), targeting both provides better functional recovery than targeting either alone. Sterile $\alpha$ and TIR motifcontaining protein 1 (Sarm1) has been found to be critical for C C G C G

\section{C2 sgRNA}

Genomic indel frequency

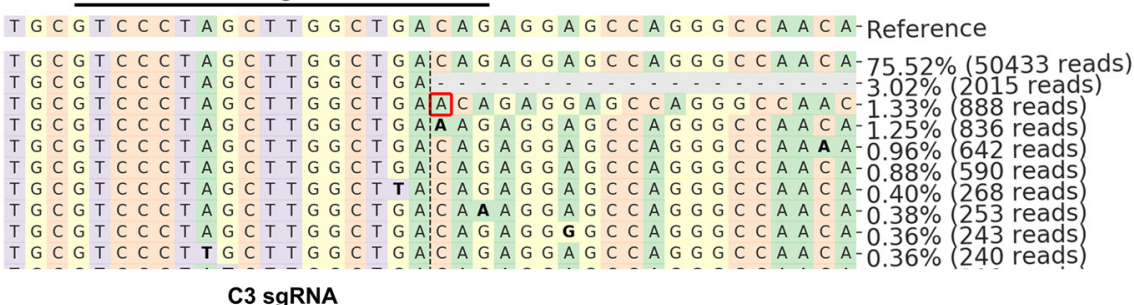

C3 sgRNA

C C CTCGCTCTCCAGATTCCAGTCAGAGTTCTATGGCC CA G-Reference C C C T C G C T C T C CA G A T T C C A G G C A G A G T T C T A T G G C C C A G $-1.45 \%$

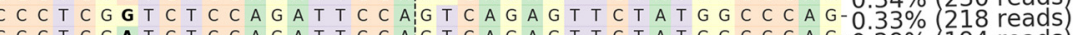
C C C T C G C T T T C CA A A T T C C A G T C A G A G T T C T A T G G C C C A G - $0.28 \%$ $\begin{array}{lllll} & \end{array}$

\section{S3 sgRNA}

C C G $\overline{C G T G G C G C G C A T C G G T C T A G}$ G C G T A T C T T G A A C C T G-Reference C GC GT G GCG C G C A T C G G T C T A G G C G T GA T C T T G A A C C T G $1.54 \%$ (273 reads) C G C G T G G C G C G C A T C G G T C T A G G C G T G A T C T T G A A C C T G $-1.12 \%$ (86 reads) G A T C A A G A G A T A C $-0.92 \%(71$ reads $-0.72 \%(55$ reads $\begin{array}{llll}\text { G A A C C T } & \text { G }-0.60 \% \\ \text { G A A C C C T } & -0.33 \% & 46 \text { reads } \\ 25 & \text { reads }\end{array}$ T G A A C C T G $-0.33 \%$
$T$ G A A C C T G $-0.23 \%$ (25 reads)
18 reads)

\section{S4 sgRNA}

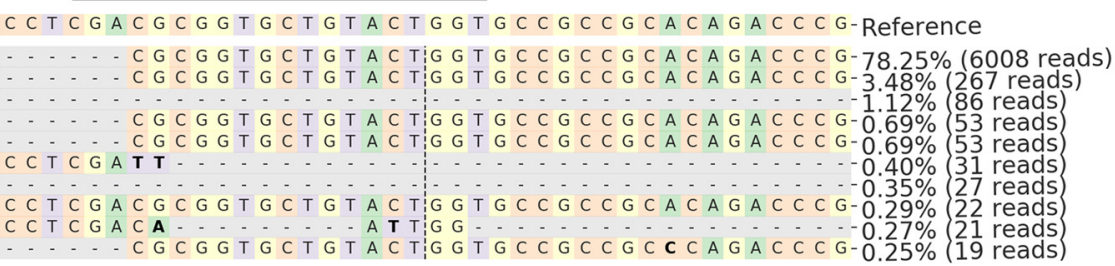

Figure 10. Sequencing results showing indels in Ddit3 and Sarm1 gRNAs' targeted regions. The representative mutation patterns and corresponding ratios in total reads detected by deep sequencing.

axon degeneration, and its deletion reported to preserve the integrity of injured axons (Osterloh et al., 2012; Gerdts et al., 2013). Therefore, Ddit3 and Sarm1 are promising targets for neuroprotection of injured RGCs and their $\mathrm{ON}$ axons. Therefore, we tested the effects of knocking down these two genes with CRISPR/Cas9 in RGCs. First, we designed several gRNAs that target Ddit3 and Sarm1 coding regions (Fig. 7A-C), tested them in cultured cells (Fig. 7D) and selected 2 gRNAs for each gene that showed strong inhibition of overexpressed Ddit3mCherry and Sarm1-mCherry. We used these total four gRNAs to make a Ddit3 and Sarm1 (C/S) gRNAs AAV vector that also contains Syn1-GFP to label the cells with gRNA expression. The AAV2-U6-C/S gRNAs-Syn1-GFP will target both genes with paired gRNAs at the same time. "Cas-OFFinder" found no potential off-targets based on "All" (Hsu et al., 2013) and "Seed" (Cong et al., 2013) criteria, except one with three mismatches that we also checked with Surveyor assay. The mSncg- $0.27 \mathrm{~kb}$ promoter allowed us to package SpCas9 into AAV2 vector and test its gene editing efficiency in RGCs in vivo. We confirmed the expression of HA-SpCas9 in RGCs after AAV-mSncg-HASpCas9 intravitreal injection (Fig. 8A, top panel). Co-injection of AAV-SpCas9 + AAV-U6-C/S gRNAs-Syn1-GFP + AAV-Ddit3mCherry in WT mouse eyes consistently produced significantly greater downregulation of Ddit3-mCherry than control-gRNA (Fig. $8 A$, bottom panel). In a separate approach, we tested Cre expression driven by full-length mSncg promoter in LSL-Flag-SpCas9 mouse 
A Surveyor assays of mouse P19 cells

DNA

ladder

(bp) Control Ddit3

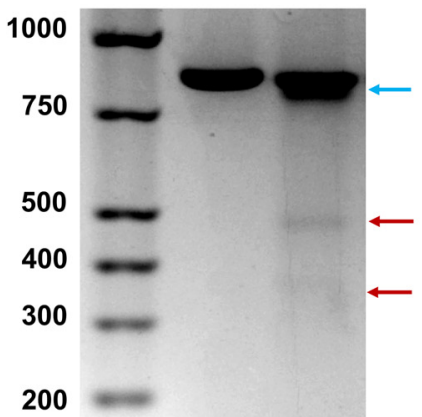

Indel (\%)

$$
3.9
$$

DNA

ladder

(bp) Control Sarm1

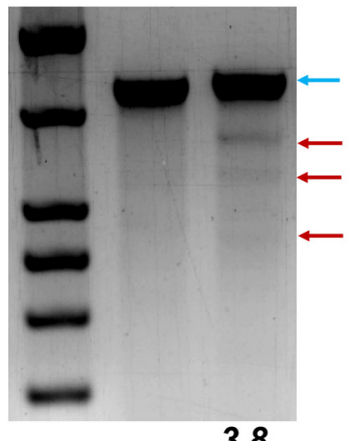

3.8

B Double gRNAs deletion in P19 cells

DNA

ladder

(bp) Ddit3

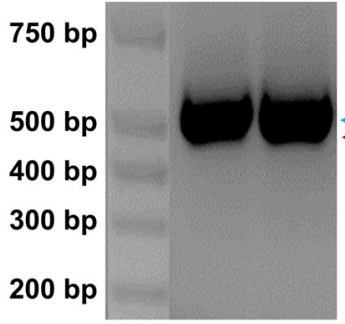

C $\longleftarrow$ WT band

- Deletion band

49 bp deleted
DNA

ladder

(bp) Sarm1

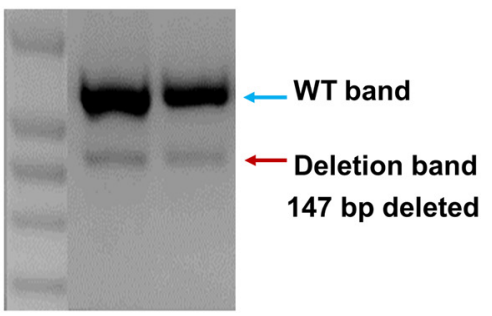

Targeted deep-sequencing of $\mathrm{P} 19$ cells

Ddit3

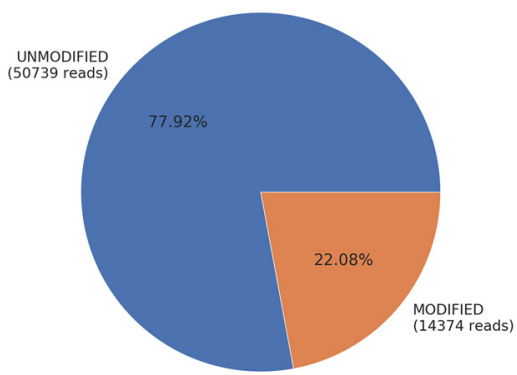

Mutation position distribution

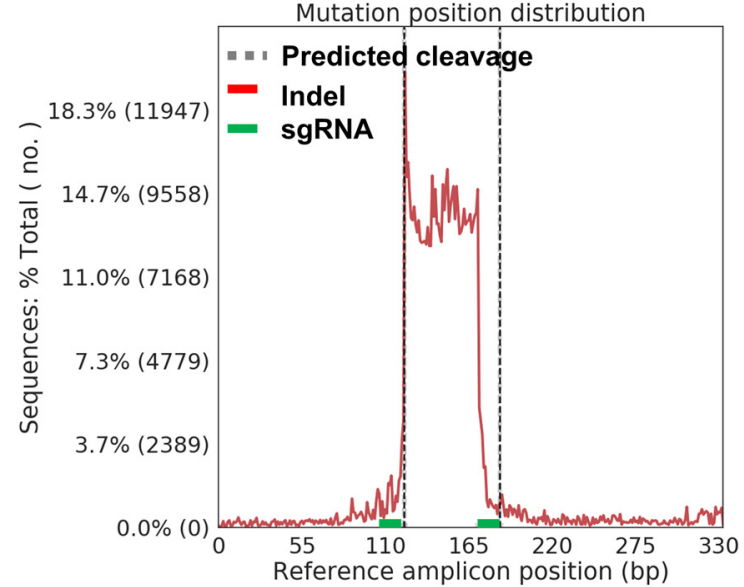

Sarm1

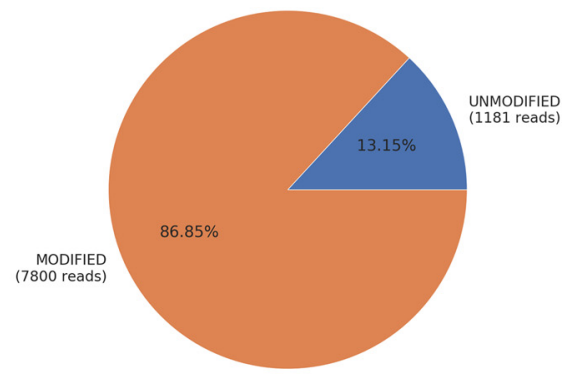

Mutation position distribution

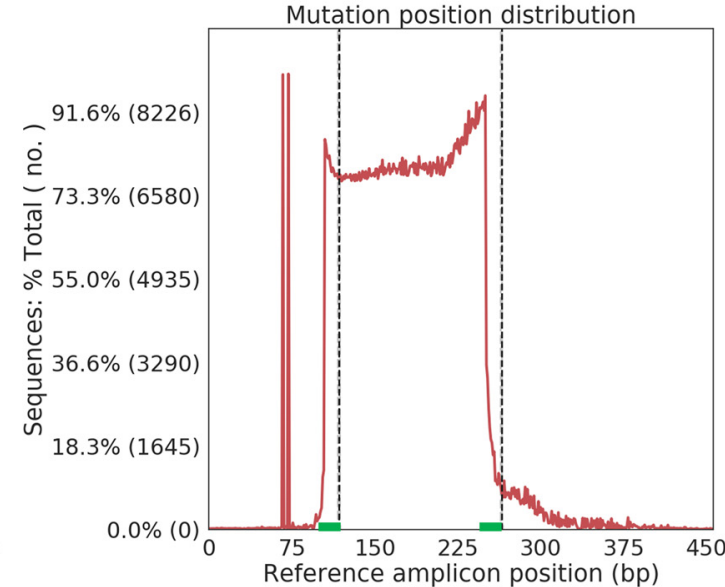

Figure 11. The efficiencies of Ddit3 and Sarm1 genomic editing in mouse P19 cell line by CRISPR/Cas9. A, Surveyor assay revealing indel formation at the Ddit3 and Sarm1 genomic locus in mouse P19 cells after transfection with C/S gRNA and Cas9. Blue arrows are WT bands; red arrows are indel bands. B, Representative gel images showing WT and deletion bands of Ddit3 and 
eyes and confirmed Flag-SpCas9 expression in RGCs (Fig. 8B, top panel). This strategy also enabled us to detect significant inhibition of Sarm1-mCherry expression after combined injection of AAVU6-C/S gRNAs-Syn1-GFP + AAV-Sarm1-mCherry in RGCs (Fig. $8 B$, bottom panel). Lastly, we used ISH and immunostaining to confirm that AAV-mSncg mediated CRISPR/Cas9 gene editing efficiently and specifically knocked down endogenous Ddit3 and Sarm1 in RGCs (Fig. 8C,D). Because basal levels of Ddit3 and Sarm 1 are very low in RGCs, the effects of knock-down were more obvious at $3 \mathrm{~d}$ postcrush (dpc), when crush injury has induced Ddit3 expression as we showed before (Hu et al., 2012).

To confirm that the downregulation of Ddit3 and Sarm1 is indeed through genomic editing in vivo, we purified GFP+ RGCs that with AAV-U6-C/S gRNAs-Syn1-GFP expression by FACS (Fig. 9A) and extracted gDNA for further analysis. Surveyor assays clearly revealed the formation of indels in the $\mathrm{C} /$ $\mathrm{S}$ gRNAs' targeted regions of Ddit3 and Sarm1 gDNA, but not in the off-target region (Fig. 9B). Since paired gRNAs were used to target each gene, a truncation of the gDNA in between the two targeted sequences of each gene is predicted (Fig. 7C). Indeed, we detected truncated bands by PCR amplification of the corresponding regions of Ddit3 and Sarm1 (Fig. 9C). Deep sequencing to determine the mutation patterns and corresponding ratios further confirmed these patterns (Fig. 10). The modification rate of Ddit3 gDNA in between the two gRNA targeted regions was $\sim 11 \%$, whereas the modification rate of Sarm 1 was much higher, $\sim 94 \%$ (Fig. 9D). The huge difference in modification rates of Ddit3 and Sarm1 gRNAs is further confirmed in a mouse P19 cell line (Fig. 11), indicating the much higher efficiency of Sarm1 gRNAs for endogenous genome editing.

\section{AAV-mSncg-CRISPR/Cas9-mediated Ddit3/Sarm 1 knock- down protects RGCs and on after acute on crush injury} With these tools in hand, we were able to perform a proof-ofconcept study testing whether RGC-targeted, AAV-mSncgCRISPR/Cas9 mediated gene editing can provide neuroprotective gene therapy for $\mathrm{ON}$ injuries. We crushed $\mathrm{ON}$ in mice that expressed control gRNA or C/S gRNAs together with SpCas9 expression mediated by AAV-mSncg-0.27K-SpCas 9 in WT mice or AAV-mSncg-Cre in LSL-Flag-SpCas9 mice. As a biomarker for the integrity of RGCs, we measured thickness of the ganglion cell complex (GCC, including RNFL, GCL, and IPL), with live OCT imaging (Fig. 12A). At two weeks after ON crush, there was $\sim 20 \%$ GCC thinning in control mouse eyes, indicating severe degeneration of RGC somata and axons (Fig. 12A,B). In contrast, $\mathrm{C} / \mathrm{S}$ gRNAs expression together with $\mathrm{mSncg}$-mediated Cas9 expression significantly increased the thickness of GCC in LSL-Cas9 mice or WT mice (Fig. 12A,B). Consistent with these in vivo results, histologic studies also demonstrated significant neuroprotection of RGC somata and axons: more RGCs survived in retina and axons in ON after AAV-mSncg-CRISPR/Cas9mediated Ddit3/Sarm1 knock-down than in control mice (Fig. $12 C-F)$. Interestingly, more RGCs survived in WT mice injected with AAV-mSncg-Cas9 than in LSL-Cas9 mice injected with AAV-mSncg-Cre,

$\leftarrow$

Sarm1. Blue arrows are WT bands; red arrows are deletion bands. C, Schematic illustration of the insertion/deletion ratio and position distribution in the targeted regions of C/S gRNAs in mouse Ddit3 and Sarm1 locus, detected by deep sequencing.

\section{Discussion}

Through a low-throughput screening, we identified and characterized the mSncg promoter as an RGC-specific promoter and demonstrated its specificity and potency in driving transgene expression in mouse RGCs. Although AAV-mediated CRISPR/ Cas9 gene deletion has been successfully applied to retina neurons before (Hung et al., 2016; Yu et al., 2017), we are the first to report specific targeting and CRISPR/Cas9 gene editing of RGCs in vivo. By applying these novel tools to the $\mathrm{ON}$ crush in vivo axon injury model, we were able to demonstrate that the effective Ddit3 and Sarm1 inhibition with AAV-mSncg-mediated CRISPR/Cas9 represents a promising gene therapy strategy for $\mathrm{RGC/ON}$ protection.

AAV-mediated inhibition of degenerative genes and enhancement of neuroprotective genes has much broader applications in treating of neurodegenerative diseases than correcting the pathogenetic mutation of a single gene. Because of their universal activities, CMV and hybrid CMV early enhancer/chicken $\beta$-actin promoter $(\mathrm{CAG})$ are often used for driving transgene expression in AAV vectors (Schön et al., 2015). Human trials with AAV2ND4 (NADH dehydrogenase, subunit 4) for Leber's hereditary optic neuropathy (LHON) are currently generating promising initial data (Feuer et al., 2016; Yang et al., 2016b; Guy et al., 2017). However, some of the beneficial effects are transient, which may be because transgene expression driven by small CMV chicken $\beta$-actin promoter is short-lived. The relatively specific and highly potent $\mathrm{mSncg}$ promoter may therefore be a better choice for future clinical trials delivering genetic materials to RGCs, including overexpression and knocking down specific genes to determine their RGC autonomous effects. Since RBPMS expression is quite stable and reliably detected by antibody in adult RGCs, it is puzzling that the genome sequence surrounding RBPMS TSS has no promoter activity at all. The real RBPMS promoter may be located far away from the RBPMS TSS or another regulatory element, such as a specific enhancer, may be needed to allow its full function. This question certainly warrants further investigation.

The synuclein proteins are chaperones in neurons, and Sncg is highly enriched in RGCs (Farkas et al., 2004; Trimarchi et al., 2007; Buckingham et al., 2008; Soto et al., 2008). Human Sncg promoter has recently been used to drive channelrhodopsin gene expression in macaque RGCs (Chaffiol et al., 2017). Because our data showed that the activity of $\mathrm{mSncg}$ promoter exceeded that of hSncg promoter in all varieties of RGCs that we studied, including mouse RGCs, hPSC-derived human RGCs, human primary RGCs, and human stem cell-derived RGCs, it would be interesting to test whether mSncg promoter is also more effective than hSncg promoter in non-human primate RGCs. Interestingly, recent findings also suggest that synthetic promoters show strong species specificity (Juttner, 2019). Although the mSncg promoter showed strong specificity for RGCs, it did not drive gene expression exclusively in RGCs (Fig. 4).

Our screening results also suggest that the specificity and potency of promoters from RGC-specific genes can be highly variable. This variability could be due to the particular characteristics of the promoter regions that we examined, or because RGCs contain additional enhancers that can affect specific promoter activity. To systematically identify additional RGC-specific genes or RGC-specific cis-regulatory elements, including promoters, enhancers and silencers, the highly efficient RGC targeting by AAV-mSncg-Cre can be combined with floxed mouse lines. Useful lines would include the RiboTag mouse (Sanz et al., 2009), which could be used to isolate RGC-specific ribosomes for translatome profiling, or the SUN1-sfGFP-Myc mouse (Mo et al., 2015) to isolate RGC-specific nuclei for epigenomic studies. 
A
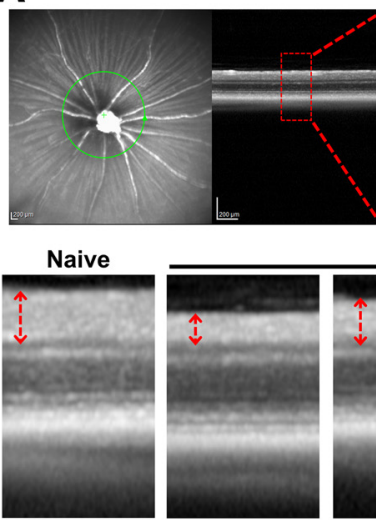

OCT

RNFL

GCC GCLIPL
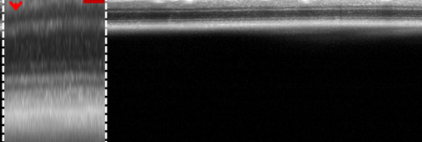

$14 \mathrm{dpc}$

Control-

gRNA

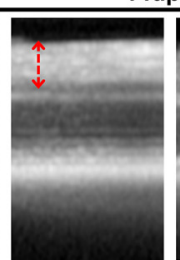

C/S-

gRNAs

AAV-mSncg-Cre in LSL-Flag-SpCas9 mice

C
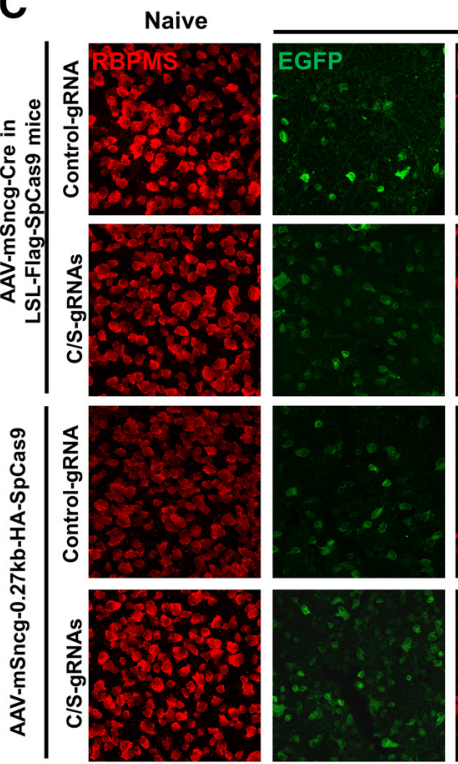

D

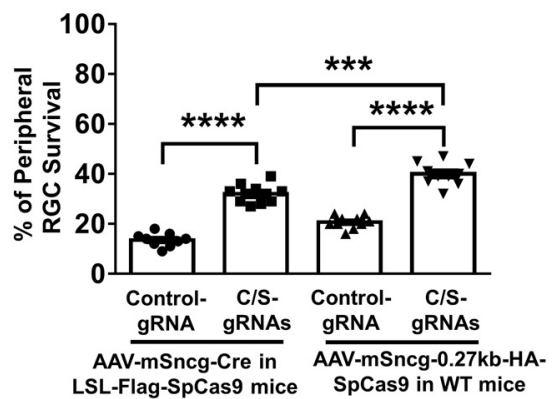

B

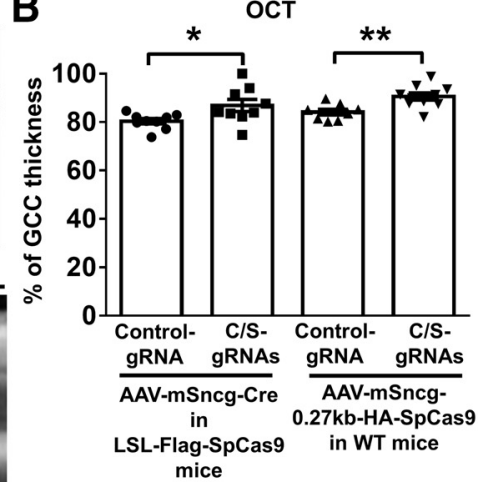

mice

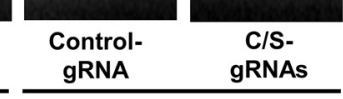

AAV-mSncg-0.27kbHA-SpCas9 in WT mice $14 \mathrm{dpc}$
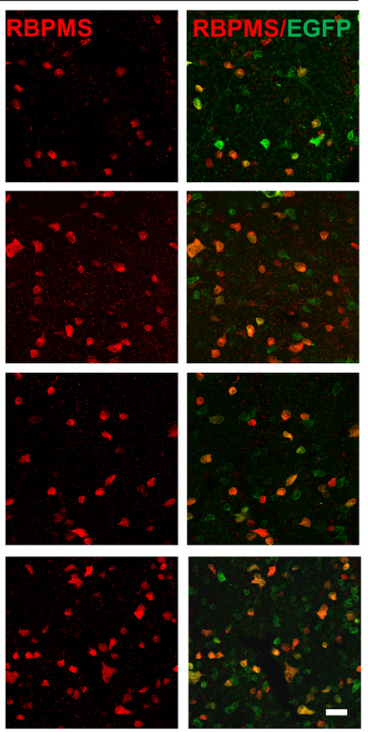

$\mathbf{F}$

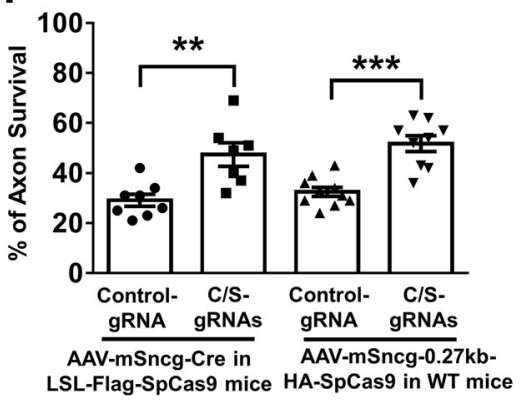

Figure 12. AAV-mSncg-CRISPR/Cas9 mediated Ddit3/Sarm1 inhibition promotes significant RGC soma and axon survival after ON crush injury. $\boldsymbol{A}$, Representative $0 \mathrm{CT}$ images of mouse retina. Green circle: indicator of the ring scanned circumpapillary region of the retina. GCC: ganglion cell complex, including RNFL, GCL, and IPL layers. $B$, Quantification of GCC thickness, represented as percentage of GCC thickness in the injured eyes, compared with the intact contralateral eye. Data are presented as mean \pm SEM, $n=8-10$; ${ }^{*} p<0.05$, ** $p<0.01$, Student's $t$ test. C, Confocal images of wholemount retinas showing surviving EGFP positive (gRNA expressed cells) and RBPMS-positive (red) RGCs, Scale bar, $20 \mu \mathrm{m}$. AAVs were injected intravitreally two weeks before $\mathrm{ON}$ crush and mice were killed $14 \mathrm{dpc}$. E, Light microscope images of semi-thin transverse sections of ON with PPD staining. Scale bar, $10 \mu \mathrm{m}$. $\boldsymbol{D}, \boldsymbol{F}$, Quantification of surviving RGC somata and axons, represented as percentage of crush injured eyes compared with the sham contralateral control eyes. Data are presented as mean \pm SEM and $n=7-10$; ** $<0.01$, ${ }^{* * *} p<0.001,{ }^{* * *} p<0.0001$; one-way ANOVA with Tukey's post hoc test.

Either of these strategies would obviate the need for disruptive and potentially confounding retinal cell dissociation. We anticipate that these RGC-specific genomic and epigenomic studies will yield more RGC-specific genes/promoters/enhancers that will find broad application in RGC-related basic and translational research.

CRISPR/Cas9 has been used for photoreceptor gene editing with photoreceptor-specific promoters (Yu et al., 2017; Maeder 
et al., 2019). Here, we demonstrate that the mSncg promoter can drive CRISPR/Cas9 specifically in RGCs, that this strategy can effectively knock down two genes, Ddit3 and Sarm1, at the same time and that it can provide significant neuroprotection for injured RGCs and ON. This success will encourage similar testing of additional neuroprotective or regenerative genetic targets for neural repair in optic neuropathies. We found that RGC protection by Ddit3 gRNA was less effective than Ddit3 total KO (Hu et al., 2012). This difference could be explained by the relatively low genomic indel ratio. Although the gRNAs are effectively knock down overexpressed Ddit3 (Fig. $8 A, D$ ), the genomic modification of endogenous Ddit3 in RGCs in vivo is only $\sim 11 \%$ (Fig. 9D) and similar result from mouse P19 cell line (Fig. 11). These results suggest that certain gene loci may be difficult to access by gRNAs/Cas9. The Sarm1 gRNAs expressed from the same vector as Ddit3 gRNAs modify the Sarm1 genome much more efficiently, consistent with easier access. Another possibility is that expression of four gRNAs may be less effective from one vector, although four U6 promoters were used to drive individual gRNA expression. This notion is difficult to test directly as there is no reliable way to measure gRNA expression. Instead, expressing single or double Ddit3 gRNAs with one AAV vector and testing its effect on endogenous Ddit3 genomic modification may be more informative. Another concern for CRISPR/Cas9 gene editing is the long-term effect. A strategy to stop Cas9 expression after the wanted gene editing may be needed as a safeguard to limit unspecific off-target effects.

Although the full-length $\mathrm{mSncg}$ promoter was more specific for RGCs, we switched to a shorter one to accommodate a larger proposed payload, SpCas9. However, S. Aureus Cas9 (SaCas9; Ran et al., 2015), which is $\sim 70 \%$ of the size of SpCas9, could be incorporated more easily into the AAV vector along with the mSncg promoter. RNA-guided endonuclease Cas9 has been repurposed for transcriptional inhibition and activation using catalytically dead Cas9 (dCas9; Qi et al., 2013; Gilbert et al., 2014; La Russa and Qi, 2015; Gao et al., 2016; Chen and Qi, 2017; Joung et al., 2017), but the much larger size of transcriptional activator/inhibitor-fused dCas9 currently precludes incorporating dCas9 into AAV vectors. However, it may be possible to package a split dCas9 system in two AAV vectors, an approach that is currently under development.

In summary, identification of this highly efficient RGC-specific promoter and the promising results demonstrated in the present proof-of-concept example of CRISPR/Cas9-mediated neuroprotection, advance the important goal of treating optic neuropathies with cell-specific gene therapy.

\section{References}

Bainbridge JW, Smith AJ, Barker SS, Robbie S, Henderson R, Balaggan K, Viswanathan A, Holder GE, Stockman A, Tyler N, Petersen-Jones S, Bhattacharya SS, Thrasher AJ, Fitzke FW, Carter BJ, Rubin GS, Moore AT, Ali RR (2008) Effect of gene therapy on visual function in Leber's congenital amaurosis. N Engl J Med 358:2231-2239.

Bakondi B, Lv W, Lu B, Jones MK, Tsai Y, Kim KJ, Levy R, Akhtar AA, Breunig JJ, Svendsen CN, Wang S (2016) In vivo CRISPR/Cas9 gene editing corrects retinal dystrophy in the S334ter-3 rat model of autosomal dominant retinitis pigmentosa. Mol Ther 24:556-563.

Balcer LJ, Miller DH, Reingold SC, Cohen JA (2015) Vision and visionrelated outcome measures in multiple sclerosis. Brain 138:11-27.

Barres BA, Silverstein BE, Corey DP, Chun LL (1988) Immunological, morphological, and electrophysiological variation among retinal ganglion cells purified by panning. Neuron 1:791-803.

Boye SE, Boye SL, Lewin AS, Hauswirth WW (2013) A comprehensive review of retinal gene therapy. Mol Ther 21:509-519.
Buckingham BP, Inman DM, Lambert W, Oglesby E, Calkins DJ, Steele MR, Vetter ML, Marsh-Armstrong N, Horner PJ (2008) Progressive ganglion cell degeneration precedes neuronal loss in a mouse model of glaucoma. J Neurosci 28:2735-2744.

Busskamp V, Duebel J, Balya D, Fradot M, Viney TJ, Siegert S, Groner AC, Cabuy E, Forster V, Seeliger M, Biel M, Humphries P, Paques M, Mohand-Said S, Trono D, Deisseroth K, Sahel JA, Picaud S, Roska B (2010) Genetic reactivation of cone photoreceptors restores visual responses in retinitis pigmentosa. Science 329:413-417.

Carelli V, La Morgia C, Ross-Cisneros FN, Sadun AA (2017) Optic neuropathies: the tip of the neurodegeneration iceberg. Hum Mol Genet 26: R139-R150.

Chaffiol A, Caplette R, Jaillard C, Brazhnikova E, Desrosiers M, Dubus E, Duhamel L, Macé E, Marre O, Benoit P, Hantraye P, Bemelmans AP, Bamberg E, Duebel J, Sahel JA, Picaud S, Dalkara D (2017) A new promoter allows optogenetic vision restoration with enhanced sensitivity in macaque retina. Mol Ther 25:2546-2560.

Chen M, Qi LS (2017) Repurposing CRISPR system for transcriptional activation. Adv Exp Med Biol 983:147-157.

Chiasseu M, Cueva Vargas JL, Destroismaisons L, Vande Velde C, Leclerc N, Di Polo A (2016) Tau accumulation, altered phosphorylation, and missorting promote neurodegeneration in glaucoma. J Neurosci 36:57855798.

Chiou SH, Winters IP, Wang J, Naranjo S, Dudgeon C, Tamburini FB, Brady JJ, Yang D, Grüner BM, Chuang CH, Caswell DR, Zeng H, Chu P, Kim GE, Carpizo DR, Kim SK, Winslow MM (2015) Pancreatic cancer modeling using retrograde viral vector delivery and in vivo CRISPR/Cas9-mediated somatic genome editing. Genes Dev 29:1576-1585.

Clement K, Rees H, Canver MC, Gehrke JM, Farouni R, Hsu JY, Cole MA, Liu DR, Joung JK, Bauer DE, Pinello L (2019) CRISPResso2 provides accurate and rapid genome editing sequence analysis. Nat Biotechnol 37:224-226.

Conforti L, Gilley J, Coleman MP (2014) Wallerian degeneration: an emerging axon death pathway linking injury and disease. Nat Rev Neurosci 15:394-409.

Cong L, Ran FA, Cox D, Lin S, Barretto R, Habib N, Hsu PD, Wu X, Jiang W, Marraffini LA, Zhang F (2013) Multiplex genome engineering using CRISPR/Cas systems. Science 339:819-823.

DeBusk A, Moster ML (2018) Gene therapy in optic nerve disease. Curr Opin Ophthalmol 29:234-238.

Ellis EM, Gauvain G, Sivyer B, Murphy GJ (2016) Shared and distinct retinal input to the mouse superior colliculus and dorsal lateral geniculate nucleus. J Neurophysiol 116:602-610.

Farkas RH, Qian J, Goldberg JL, Quigley HA, Zack DJ (2004) Gene expression profiling of purified rat retinal ganglion cells. Invest Ophthalmol Vis Sci 45:2503-2513.

Favaro P, Finn JD, Siner JI, Wright JF, High KA, Arruda VR (2011) Safety of liver gene transfer following peripheral intravascular delivery of adenoassociated virus (AAV)-5 and AAV-6 in a large animal model. Hum Gene Ther 22:843-852.

Feuer WJ, Schiffman JC, Davis JL, Porciatti V, Gonzalez P, Koilkonda RD, Yuan H, Lalwani A, Lam BL, Guy J (2016) Gene therapy for Leber hereditary optic neuropathy: initial results. Ophthalmology 123:558-570.

Fligor CM, Langer KB, Sridhar A, Ren Y, Shields PK, Edler MC, Ohlemacher SK, Sluch VM, Zack DJ, Zhang C, Suter DM, Meyer JS (2018) Threedimensional retinal organoids facilitate the investigation of retinal ganglion cell development, organization and neurite outgrowth from human pluripotent stem cells. Sci Rep 8:14520.

Gao Y, Xiong X, Wong S, Charles EJ, Lim WA, Qi LS (2016) Complex transcriptional modulation with orthogonal and inducible dCas9 regulators. Nat Methods 13:1043-1049.

Gerdts J, Summers DW, Sasaki Y, DiAntonio A, Milbrandt J (2013) Sarm1mediated axon degeneration requires both SAM and TIR interactions. J Neurosci 33:13569-13580.

Gerdts J, Summers DW, Milbrandt J, DiAntonio A (2016) Axon self-destruction: new links among SARM1, MAPKs, and NAD1 metabolism. Neuron 89:449-460.

Gerits A, Vancraeyenest P, Vreysen S, Laramée ME, Michiels A, Gijsbers R, Van den Haute C, Moons L, Debyser Z, Baekelandt V, Arckens L, Vanduffel W (2015) Serotype-dependent transduction efficiencies of recombinant adeno-associated viral vectors in monkey neocortex. Neurophotonics 2:031209. 
Gilbert LA, Horlbeck MA, Adamson B, Villalta JE, Chen Y, Whitehead EH, Guimaraes C, Panning B, Ploegh HL, Bassik MC, Qi LS, Kampmann M, Weissman JS (2014) Genome-scale CRISPR-mediated control of gene repression and activation. Cell 159:647-661.

Gorbatyuk MS, Knox T, LaVail MM, Gorbatyuk OS, Noorwez SM, Hauswirth WW, Lin JH, Muzyczka N, Lewin AS (2010) Restoration of visual function in $\mathrm{P} 23 \mathrm{H}$ rhodopsin transgenic rats by gene delivery of BiP/Grp78. Proc Natl Acad Sci USA 107:5961-5966.

Guy J, Feuer WJ, Davis JL, Porciatti V, Gonzalez PJ, Koilkonda RD, Yuan H, Hauswirth WW, Lam BL (2017) Gene therapy for leber hereditary optic neuropathy: low- and medium-dose visual results. Ophthalmology 124:1621-1634.

Hastie E, Samulski RJ (2015) Adeno-associated virus at 50: a golden anniversary of discovery, research, and gene therapy success-a personal perspective. Hum Gene Ther 26:257-265.

Hauswirth WW, Aleman TS, Kaushal S, Cideciyan AV, Schwartz SB, Wang L, Conlon TJ, Boye SL, Flotte TR, Byrne BJ, Jacobson SG (2008) Treatment of leber congenital amaurosis due to RPE65 mutations by ocular subretinal injection of adeno-associated virus gene vector: short-term results of a phase I trial. Hum Gene Ther 19:979-990.

Howell GR, Soto I, Libby RT, John SW (2013) Intrinsic axonal degeneration pathways are critical for glaucomatous damage. Exp Neurol 246:54-61.

Hsu PD, Scott DA, Weinstein JA, Ran FA, Konermann S, Agarwala V, Li Y, Fine EJ, Wu X, Shalem O, Cradick TJ, Marraffini LA, Bao G, Zhang F (2013) DNA targeting specificity of RNA-guided Cas9 nucleases. Nat Biotechnol 31:827-832.

Hu Y, Park KK, Yang L, Wei X, Yang Q, Cho K-S, Thielen P, Lee A-H, Cartoni R, Glimcher LH, Chen DF, He Z (2012) Differential effects of unfolded protein response pathways on axon injury-induced death of retinal ganglion cells. Neuron 73:445-452.

Huang H, Miao L, Liang F, Liu X, Xu L, Teng X, Wang Q, Ridder WH 3rd, Shindler KS, Sun Y, Hu Y (2017) Neuroprotection by eIF2 $\alpha$-CHOP inhibition and XBP-1 activation in EAE/optic neuritiss. Cell Death Dis 8: e2936.

Hung SS, Chrysostomou V, Li F, Lim JK, Wang JH, Powell JE, Tu L, Daniszewski M, Lo C, Wong RC, Crowston JG, Pébay A, King AE, Bui BV, Liu GS, Hewitt AW (2016) AAV-mediated CRISPR/Cas gene editing of retinal cells in vivo. Invest Ophthalmol Vis Sci 57:3470-3476.

Jinek M, East A, Cheng A, Lin S, Ma E, Doudna J (2013) RNA-programmed genome editing in human cells. Elife 2:e00471.

Joung J, Konermann S, Gootenberg JS, Abudayyeh OO, Platt RJ, Brigham MD, Sanjana NE, Zhang F (2017) Genome-scale CRISPR-Cas9 knockout and transcriptional activation screening. Nat Protoc 12:828-863.

Juttner J (2019) Targeting neuronal and glial cell types with synthetic promoter AAVs in mice, non-human primates and humans. Nat Neurosci 22:1345-1356

Keeler AM, ElMallah MK, Flotte TR (2017) Gene therapy 2017: progress and future directions. Clin Transl Sci 10:242-248.

Kügler S, Lingor P, Schöll U, Zolotukhin S, Bähr M (2003) Differential transgene expression in brain cells in vivo and in vitro from AAV-2 vectors with small transcriptional control units. Virology 311:89-95.

Kwong JM, Caprioli J, Piri N (2010) RNA binding protein with multiple splicing: a new marker for retinal ganglion cells. Invest Ophthalmol Vis Sci 51:1052-1058

La Russa MF, Qi LS (2015) The new state of the art: cas9 for gene activation and repression. Mol Cell Biol 35:3800-3809.

Maeder ML, Stefanidakis M, Wilson CJ, Baral R, Barrera LA, Bounoutas GS, Bumcrot D, Chao H, Ciulla DM, DaSilva JA, Dass A, Dhanapal V, Fennell TJ, Friedland AE, Giannoukos G, Gloskowski SW, Glucksmann A, Gotta GM, Jayaram H, Haskett SJ, et al. (2019) Development of a gene-editing approach to restore vision loss in Leber congenital amaurosis type 10. Nat Med 25:229-233.

Maguire AM, Simonelli F, Pierce EA, Pugh EN, Mingozzi F, Bennicelli J, Banfi S, Marshall KA, Testa F, Surace EM, Rossi S, Lyubarsky A, Arruda VR, Konkle B, Stone E, Sun J, Jacobs J, Dell'Osso L, Hertle R, Ma JX, et al. (2008) Safety and efficacy of gene transfer for Leber's congenital amaurosis. N Engl J Med 358:2240-2248.

Maguire AM, High KA, Auricchio A, Wright JF, Pierce EA, Testa F, Mingozzi F, Bennicelli JL, Ying GS, Rossi S, Fulton A, Marshall KA, Banfi S, Chung DC, Morgan JIW, Hauck B, Zelenaia O, Zhu X, Raffini L, Coppieters F, et al. (2009) Age-dependent effects of RPE65 gene therapy for Leber's congenital amaurosis: a phase 1 dose-escalation trial. Lancet 374:1597-1605.

Mali P, Yang L, Esvelt KM, Aach J, Guell M, DiCarlo JE, Norville JE, Church GM (2013) RNA-guided human genome engineering via Cas9. Science 339:823-826.

Mayford M, Baranes D, Podsypanina K, Kandel ER (1996) The 3'-untranslated region of CaMKII alpha is a cis-acting signal for the localization and translation of mRNA in dendrites. Proc Natl Acad Sci USA 93:13250-13255.

McKinnon SJ (2003) Glaucoma: ocular Alzheimer's disease? Front Biosci 8: s1140-s1156.

Mellough CB, Cui Q, Spalding KL, Symons NA, Pollett MA, Snyder EY, Macklis JD, Harvey AR (2004) Fate of multipotent neural precursor cells transplanted into mouse retina selectively depleted of retinal ganglion cells. Exp Neurol 186:6-19.

Meyer RL, Miotke JA, Benowitz LI (1994) Injury induced expression of growth-associated protein-43 in adult mouse retinal ganglion cells in vitro. Neuroscience 63:591-602.

Miao L, Yang L, Huang H, Liang F, Ling C, Hu Y (2016) mTORC1 is necessary but mTORC2 and GSK3 $\beta$ are inhibitory for AKT3-induced axon regeneration in the central nervous system. Elife 5:e14908.

Minegishi Y, Nakayama M, Iejima D, Kawase K, Iwata T (2016) Significance of optineurin mutations in glaucoma and other diseases. Prog Retin Eye Res 55:149-181.

Mingozzi F, High KA (2011) Therapeutic in vivo gene transfer for genetic disease using AAV: progress and challenges. Nat Rev Genet 12:341-355.

Mo A, Mukamel EA, Davis FP, Luo C, Henry GL, Picard S, Urich MA, Nery JR, Sejnowski TJ, Lister R, Eddy SR, Ecker JR, Nathans J (2015) Epigenomic signatures of neuronal diversity in the mammalian brain. Neuron 86:1369-1384.

Nathwani AC, Davidoff AM, Hanawa H, Hu Y, Hoffer FA, Nikanorov A, Slaughter C, Ng CY, Zhou J, Lozier JN, Mandrell TD, Vanin EF, Nienhuis AW (2002) Sustained high-level expression of human factor IX (hFIX) after liver-targeted delivery of recombinant adeno-associated virus encoding the hFIX gene in rhesus macaques. Blood 100:1662-1669.

Nickells RW, Schmitt HM, Maes ME, Schlamp CL (2017) AAV2-mediated transduction of the mouse retina after optic nerve injury. Invest Ophthalmol Vis Sci 58:6091-6104.

Ohlemacher SK, Iglesias CL, Sridhar A, Gamm DM, Meyer JS (2015) Generation of highly enriched populations of optic vesicle-like retinal cells from human pluripotent stem cells. Curr Protoc Stem Cell Biol 32:1-20.

Ohlemacher SK, Sridhar A, Xiao Y, Hochstetler AE, Sarfarazi M, Cummins TR, Meyer JS (2016) Stepwise differentiation of retinal ganglion cells from human pluripotent stem cells enables analysis of glaucomatous neurodegeneration. Stem Cells 34:1553-1562.

Osterloh JM, Yang J, Rooney TM, Fox AN, Adalbert R, Powell EH, Sheehan AE, Avery MA, Hackett R, Logan MA, MacDonald JM, Ziegenfuss JS, Milde S, Hou YJ, Nathan C, Ding A, Brown RH, Conforti L, Coleman M, Tessier-Lavigne M, et al. (2012) dSarm/Sarm1 is required for activation of an injury-induced axon death pathway. Science 337:481-484.

Pak W, Hindges R, Lim Y-S, Pfaff SL, O'Leary DDM (2004) Magnitude of binocular vision controlled by islet-2 repression of a genetic program that specifies laterality of retinal axon pathfinding. Cell 119:567-578.

Pang JJ, Lauramore A, Deng WT, Li Q, Doyle TJ, Chiodo V, Li J, Hauswirth WW (2008) Comparative analysis of in vivo and in vitro AAV vector transduction in the neonatal mouse retina: effects of serotype and site of administration. Vision Res 48:377-385.

Park KK, Liu K, Hu Y, Smith PD, Wang C, Cai B, Xu B, Connolly L, Kramvis I, Sahin M, He Z (2008) Promoting axon regeneration in the adult CNS by modulation of the PTEN/mTOR pathway. Science 322:963-966.

Petrs-Silva H, Dinculescu A, Li Q, Deng WT, Pang JJ, Min SH, Chiodo V, Neeley AW, Govindasamy L, Bennett A, Agbandje-McKenna M, Zhong L, Li B, Jayandharan GR, Srivastava A, Lewin AS, Hauswirth WW (2011) Novel properties of tyrosine-mutant AAV2 vectors in the mouse retina. Mol Ther 19:293-301.

Qi LS, Larson MH, Gilbert LA, Doudna JA, Weissman JS, Arkin AP, Lim WA (2013) Repurposing CRISPR as an RNA-guided platform for sequence-specific control of gene expression. Cell 152:1173-1183.

Ran FA, Hsu PD, Wright J, Agarwala V, Scott DA, Zhang F (2013) Genome engineering using the CRISPR-Cas9 system. Nat Protoc 8:2281-2308. 
Ran FA, Cong L, Yan WX, Scott DA, Gootenberg JS, Kriz AJ, Zetsche B, Shalem O, Wu X, Makarova KS, Koonin EV, Sharp PA, Zhang F (2015) In vivo genome editing using Staphylococcus aureus Cas9. Nature 520:186-191.

Ratican SE, Osborne A, Martin KR (2018) Progress in gene therapy to prevent retinal ganglion cell loss in glaucoma and Leber's hereditary optic neuropathy. Neural Plast 2018:7108948.

Rodriguez AR, de Sevilla Müller LP, Brecha NC (2014) The RNA binding protein RBPMS is a selective marker of ganglion cells in the mammalian retina. J Comp Neurol 522:1411-1443.

Sabatino DE, Mackenzie TC, Peranteau W, Edmonson S, Campagnoli C, Liu YL, Flake AW, High KA (2007) Persistent expression of hF.IX After tolerance induction by in utero or neonatal administration of AAV-1-F.IX in hemophilia B mice. Mol Ther 15:1677-1685.

Sabatino DE, Lange AM, Altynova ES, Sarkar R, Zhou S, Merricks EP, Franck HG, Nichols TC, Arruda VR, Kazazian HH Jr (2011) Efficacy and safety of long-term prophylaxis in severe hemophilia A dogs following liver gene therapy using AAV vectors. Mol Ther 19:442-449.

Sanz E, Yang L, Su T, Morris DR, McKnight GS, Amieux PS (2009) Celltype-specific isolation of ribosome-associated mRNA from complex tissues. Proc Natl Acad Sci USA 106:13939-13944.

Schaden H, Stuermer CA, Bähr M (1994) GAP-43 immunoreactivity and axon regeneration in retinal ganglion cells of the rat. $J$ Neurobiol 25:1570-1578

Schnepp BC, Clark KR, Klemanski DL, Pacak CA, Johnson PR (2003) Genetic fate of recombinant adeno-associated virus vector genomes in muscle. J Virol 77:3495-3504.

Schön C, Biel M, Michalakis S (2015) Retinal gene delivery by adeno-associated virus (AAV) vectors: strategies and applications. Eur J Pharm Biopharm 95:343-352.

Sluch VM, Davis CH, Ranganathan V, Kerr JM, Krick K, Martin R, Berlinicke CA, Marsh-Armstrong N, Diamond JS, Mao HQ, Zack DJ (2015) Differentiation of human ESCs to retinal ganglion cells using a CRISPR engineered reporter cell line. Sci Rep 5:16595.

Sluch VM, Chamling X, Liu MM, Berlinicke CA, Cheng J, Mitchell KL, Welsbie DS, Zack DJ (2017) Enhanced stem cell differentiation and immunopurification of genome engineered human retinal ganglion cells. Stem cells Transl Med 6:1972-1986.

Smalley E (2017) First AAV gene therapy poised for landmark approval. Nat Biotechnol 35:998-999.

Smith RS (2002) Systematic evaluation of the mouse eye: anatomy, pathology, and biomethods. Boca Raton: CRC.

Soto I, Oglesby E, Buckingham BP, Son JL, Roberson ED, Steele MR, Inman DM, Vetter ML, Horner PJ, Marsh-Armstrong N (2008) Retinal ganglion cells downregulate gene expression and lose their axons within the optic nerve head in a mouse glaucoma model. J Neurosci 28:548-561.

Spanopoulou E, Giguere V, Grosveld F (1991) The functional domains of the murine Thy-1 gene promoter. Mol Cell Biol 11:2216-2228.

Surgucheva I, Weisman AD, Goldberg JL, Shnyra A, Surguchov A (2008) Gamma-synuclein as a marker of retinal ganglion cells. Mol Vis 14:15401548.
Surguchov A, McMahan B, Masliah E, Surgucheva I (2001) Synucleins in ocular tissues. J Neurosci Res 65:68-77.

Talman LS (2010) Longitudinal study of vision and retinal nerve fiber layer thickness in multiple sclerosis. Ann Neurol 67:749-760.

Toosy AT, Mason DF, Miller DH (2014) Optic neuritis. Lancet Neurol 13:83-99.

Trimarchi JM, Stadler MB, Roska B, Billings N, Sun B, Bartch B, Cepko CL (2007) Molecular heterogeneity of developing retinal ganglion and amacrine cells revealed through single cell gene expression profiling. J Comp Neurol 502:1047-1065

Venugopalan P, Wang Y, Nguyen T, Huang A, Muller KJ, Goldberg JL (2016) Transplanted neurons integrate into adult retinas and respond to light. Nat Commun 7:10472.

Vidal M, Morris R, Grosveld F, Spanopoulou E (1990) Tissue-specific control elements of the Thy-1 gene. EMBO J 9:833-840.

Wang JT, Medress ZA, Barres BA (2012) Axon degeneration: molecular mechanisms of a self-destruction pathway. J Cell Biol 196:7-18.

Wang LN, Wang Y, Lu Y, Yin ZF, Zhang YH, Aslanidi GV, Srivastava A, Ling CQ, Ling C (2014a) Pristimerin enhances recombinant adeno-associated virus vector-mediated transgene expression in human cell lines in vitro and murine hepatocytes in vivo. J Integr Med 12:20-34.

Wang S, Sengel C, Emerson MM, Cepko CL (2014b) A gene regulatory network controls the binary fate decision of rod and bipolar cells in the vertebrate retina. Dev Cell 30:513-527.

Wang M, Kaufman RJ (2016) Protein misfolding in the endoplasmic reticulum as a conduit to human disease. Nature 529:326-335.

Wassmer SJ, Carvalho LS, György B, Vandenberghe LH, Maguire CA (2017) Exosome-associated AAV2 vector mediates robust gene delivery into the murine retina upon intravitreal injection. Sci Rep 7:45329.

Wiggs JL, Pasquale LR (2017) Genetics of glaucoma. Hum Mol Genet 26: R21-R27.

Yang L, Miao L, Liang F, Huang H, Teng X, Li S, Nuriddinov J, Selzer ME, $\mathrm{Hu}$ Y (2014) The mTORC1 effectors S6K1 and 4E-BP play different roles in CNS axon regeneration. Nat Commun 5:5416.

Yang L, Li S, Miao L, Huang H, Liang F, Teng X, Xu L, Wang Q, Xiao W, Ridder WH 3rd, Ferguson TA, Chen DF, Kaufman RJ, Hu Y (2016a) Rescue of glaucomatous neurodegeneration by differentially modulating neuronal endoplasmic reticulum stress molecules. J Neurosci 36:58915903.

Yang S, Ma SQ, Wan X, He H, Pei H, Zhao MJ, Chen C, Wang DW, Dong XY, Yuan JJ, Li B (2016b) Long-term outcomes of gene therapy for the treatment of Leber's hereditary optic neuropathy. EBioMedicine 10:258268

Yu W, Mookherjee S, Chaitankar V, Hiriyanna S, Kim JW, Brooks M, Ataeijannati Y, Sun X, Dong L, Li T, Swaroop A, Wu Z (2017) Nrl knockdown by AAV-delivered CRISPR/Cas9 prevents retinal degeneration in mice. Nat Commun 8:14716.

Zhang YH, Wang Y, Yusufali AH, Ashby F, Zhang D, Yin ZF, Aslanidi GV, Srivastava A, Ling CQ, Ling C (2014) Cytotoxic genes from traditional Chinese medicine inhibit tumor growth both in vitro and in vivo. J Integr Med 12:483-494. 